\title{
A new large cynodont from the Late Permian (Lopingian) of the South African Karoo Basin and its phylogenetic significance
}

\author{
FERNANDO ABDALA ${ }^{1,2, *}$, LEANDRO C. GAETANO ${ }^{2,3}$, ROGER M. H. SMITH ${ }^{2,4}$ and \\ BRUCE S. RUBIDGE ${ }^{2}$ \\ ${ }^{1}$ Unidad Ejecutora Lillo, Conicet-Fundación Miguel Lillo, Miguel Lillo 251, Tucumán, Argentina \\ ${ }^{2}$ Evolutionary Studies Institute and School of Geosciences, University of the Witwatersrand, \\ Johannesburg, South Africa \\ ${ }^{3}$ Departamento de Ciencias Geológicas, Facultad de Ciencias Exactas y Naturales, Instituto de Estudios \\ Andinos 'Don Pablo Groeber', IDEAN (Universidad de Buenos Aires, CONICET), Intendente Güiraldes \\ 2160, Ciudad Universitaria - Pabellón II, C1428EGA, Ciudad Autónoma de Buenos Aires, Argentina \\ ${ }^{4}$ Department of Karoo Palaeontology, Iziko South African Museum, PO Box 61, Cape Town, 8000, South \\ Africa
}

Received 22 May 2018; revised 16 December 2018; accepted for publication 24 December 2018

\begin{abstract}
The Karoo Basin of South Africa has the best global record of Lopingian (Late Permian) non-mammaliaform cynodonts, currently represented by five species. We describe Vetusodon elikhulu gen. et sp. nov., documented by four specimens from the Daptocephalus Assemblage Zone. With a basal skull length of $\sim 18 \mathrm{~cm}$, it is the largest Lopingian cynodont and is also larger than Induan representatives of the group. Vetusodon elikhulu has a cranial morphology that departs notably from that previously documented for Permo-Triassic cynodonts. It features a short and extremely wide snout, resembling that of the contemporaneous therocephalian Moschorhinus, and has large incisors and canines that contrast with the small unicusped postcanines, suggesting a more important role of the anterior dentition for feeding. The dentary is extremely long and robust, with the posterior margin located closer to the craniomandibular joint than in other Lopingian and Induan cynodonts (e.g. Thrinaxodon). The secondary palate morphology of V.elikhulu is unique, being short and incomplete and with the posterior portion of the maxilla partly covering the vomer. A phylogenetic analysis suggests that $\mathbf{V}$. elikhulu is the sister taxon of Eucynodontia and thus the most derived of the Lopingian to Induan cynodonts yet discovered.
\end{abstract}

ADDITIONAL KEYWORDS: anatomy - Changhsingian - epicynodont - Gondwana - phylogeny.

\section{INTRODUCTION}

The Palaeozoic-to-Mesozoic transition represents a landmark in the history of biota on Earth, known as the End-Permian mass extinction. Several environmental changes occurred during this time that had a particular influence on tetrapod faunas across Pangaea (Sahney \& Benton, 2008). Among the Lopingian (Late Permian) synapsids, Therapsida

*Corresponding author. E-mail: 1viutiabdala2@gmail.com [Version of Record, published online 2 May 2019; http://zoobank.org/urn:lsid:zoobank.org:pub:12C56A46A10F-4DC4-870F-D8232DE3CD6F] were the most prevalent, having been documented from every corner of the planet. Despite their global distribution, the fossil record is best known from the main Karoo Basin of South Africa (Rubidge \& Sidor, 2001), which hosts the longest and most complete fossil record of therapsids from the Middle Permian to the Early Jurassic (Smith et al., 2012). This record exhibits evolutionary transformations in the cynodont lineage that led to the origin of mammals (Rubidge \& Sidor, 2001; Kemp, 2005).

The oldest therapsids in the Karoo Basin are from the Capitanian (Late-Middle Permian) Eodicynodon and Tapinocephalus assemblage zones (AZs), where they are represented by five of the six major 
therapsid lineages (Smith et al., 2012). The sixth is the Cynodontia clade, which includes the only living forms of therapsids, the mammals. Cynodontia is first recorded in the Wuchiapingian (Early-Late Permian) Tropidostoma AZ of the southern Karoo Basin. Two genera, Charassognathus and Abdalodon, occur in this assemblage zone (Botha et al., 2007; Kammerer, 2016; van den Brandt \& Abdala, 2018), which would suggest an earlier origin for cynodonts. Toward the end of the Permian, in the Daptocephalus AZ, the number of cynodont genera had doubled. They comprise the Russian Dvinia, the more widely distributed Procynosuchus and the South African Cynosaurus and Nanictosaurus (Sues \& Boy, 1988; Rubidge, 1995, 2005; Abdala \& Allison, 2005; Weide et al., 2010). These taxa have basal skull lengths (BSLs, measured from the anterior tip of the snout to the posterior end of the occipital condyles) ranging from $5.5 \mathrm{~cm}$ in Nanictosaurus to $14 \mathrm{~cm}$ in Procynosuchus.

A sagittally sectioned pre-orbital portion of a Late Permian therapsid skull (a cast of SAM-PK-K10596) was presented by Kemp (1972) as a 'whaitsiid-cynodont' when discussing the origin of cynodonts. A second specimen representing this enigmatic form was spotted by F.A. in the collection of the Council for Geosciences in Pretoria. It is a large, incomplete skull lacking the mandible, and it was collected by Gideon Groenewald in outcrops of the Thaba Nchu Mountain in Free State Province, South Africa. A third specimen, a complete skull with articulated lower jaw, was discovered by Derik Wolvaardt and excavated by Roger Smith's research team while prospecting the Permo-Triassic boundary in Ripplemead, near Nieu Bethesda, South Africa in 2009-2010. During a field excursion after the Palaeontological Society of South Africa conference in Howick (August 2010), a fourth skull was discovered, lacking a lower jaw.

These four specimens share a number of anatomical traits that distinguish them from other previously known therapsids, representing an unknown cynodont taxon that is so far confined to the Daptocephalus AZ of the Karoo Basin. The new form, with BSL $\leq 18 \mathrm{~cm}$, is noticeably larger than any of the other Lopingianaged cynodonts. The specimen from Ripplemead was stratigraphically logged as being $20 \mathrm{~m}$ below the mass extinction beds and is the only Late Permian cynodont that has been recovered from so close to the Permo-Triassic boundary (Smith \& Botha-Brink, 2014: Supporting Information, Table S1). Here, we present this new Changhsingian (latest Permian) cynodont from the Karoo Basin and provide a detailed description of its cranial anatomy. We also explore its phylogenetic relationships in the framework of basal cynodonts. The new taxon documents a series of features that greatly modify our understanding of the early diversity and evolution of the basal members of this important lineage.

\section{INSTITUTIONAL ABBREVIATIONS}

AM, Albany Museum, Grahamstown, South Africa; BP, Evolutionary Studies Institute (formerly Bernard Price Institute), Johannesburg, South Africa; CGP GHG, Council for Geosciences, Pretoria, South Africa; NHMUK, Natural History Museum, London, UK; NMQR, National Museum, Bloemfontein, South Africa; RC, Rubidge collection, Wellwood, Graaff-Reinet, South Africa; SAM-PK, Iziko South African Museum, Cape Town, South Africa; TM, Ditsong Museum (formerly Transvaal Museum), Pretoria, South Africa; UCMZ, University Museum of Zoology, Cambridge, UK.

\section{MATERIAL AND METHODS}

The new species described here is represented by four specimens: BP/1/7971, CGP GHG141, SAMPK-K10702 and SAM-PK-K10596.

$\mathrm{BP} / 1 / 7971$ is an almost complete skull, missing only the occipital condyles, the right pterygoid process and part of the dentition (Figs 1,2). There are signs of dorsoventral compression as evidenced by the lateral distortion of the skull and badly crushed alisphenoids on either side. The snout, dorsal portion of the skull, occipital plate and basicranium are relatively well preserved, and the specimen has the best-preserved palate, dentition and stapes. Most of the sutures can be tracked, but with some effort.

SAM-PK-K10702 is a skull and articulated lower jaw (Fig. 3). Preservation is relatively good, but the bone shows surface cracks that appear as white veins. Some dorsoventral crushing is evident on the left side of the snout, where the posterior portion of the maxilla is crushed and pressed against the dentary. The ventral margin of the dentary is incomplete and eroded on both sides. The palate and basicranium are strongly deformed and poorly preserved, and both stapes are also poorly preserved. Most of the sutures are not visible.

SAM-PK-K10596 comprises only the snout of the skull (Fig. 4), which was sagittally sectioned earlier. Although there is some damage, especially dorsally, the specimen is in relatively good shape, with no apparent deformation. The palate is the best-preserved portion of the specimen. The teeth are represented only by the roots inside the alveoli except for the tip of some replacement teeth. Sutures are discernible. Dr A. W. Crompton collected SAMPK-K10596 on an expedition in 1958 or 1959. According to the discoverer, the specimen was found near Murraysburg, South Africa. However, in the South African Museum Annual Report, it is stated that the 1958-1959 expedition went to Middelburg, South Africa. Hence, the specimen most probably comes from Groote Valley 133, Grootvlei, Middelburg, 

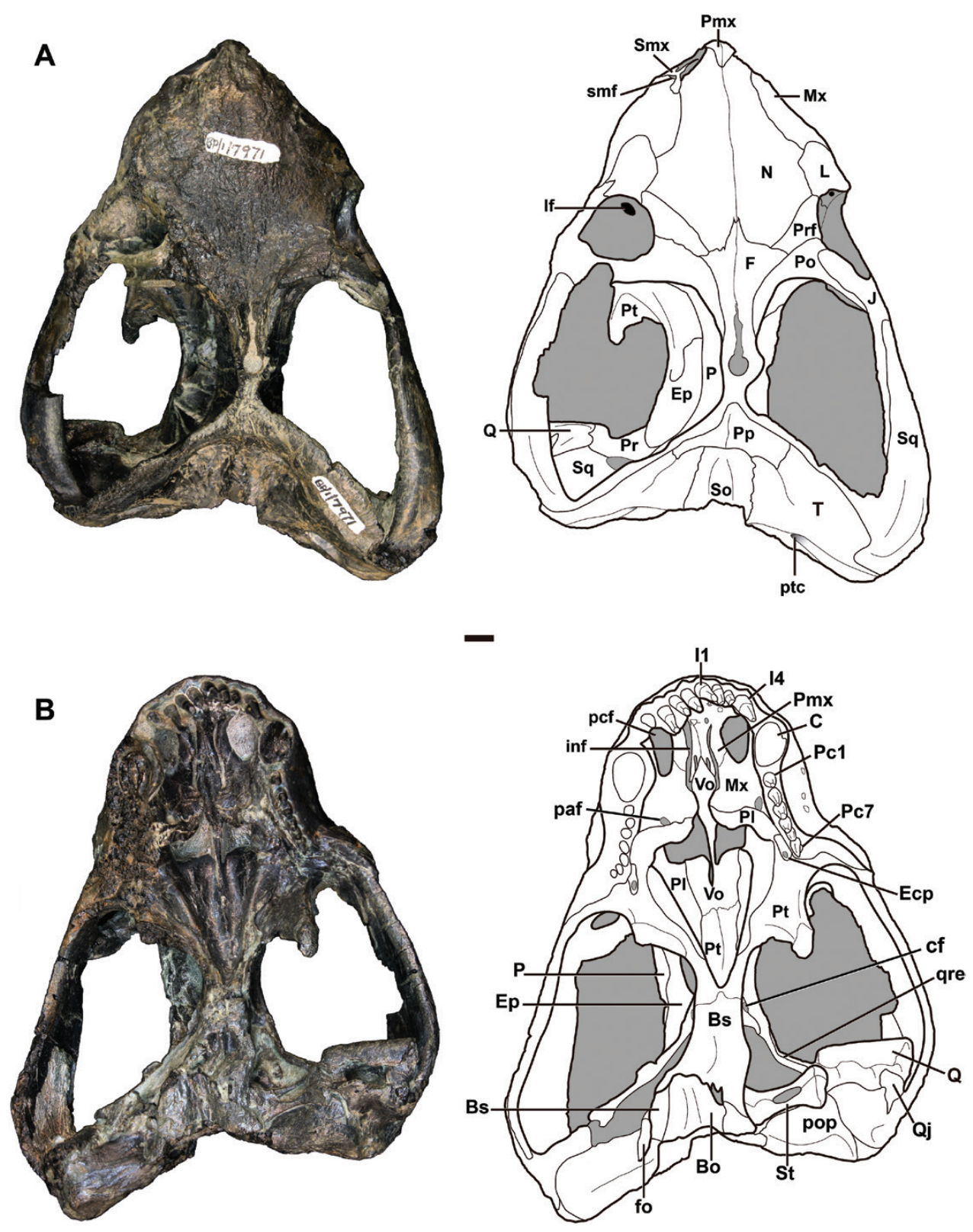

Figure 1. BP/1/7971. Skull in dorsal view (A) and ventral view (B). Abbreviations: Bo, basioccipital; Bs, basisphenoid; C, canine; cf, carotid foramen; Ecp, ectopterygoid; Ep, epipterygoid; F, frontal; fo, fenestra ovalis; I, incisive; inf, incisive foramen; J, jugal; L, lacrimal; lf, lacrimal foramen; Mx, maxilla; N, nasal; P, parietal; paf, palatal foramen; Pc, postcanine; pcf, paracanine fossa; Pl, palatine; Pmx, premaxilla; Po, postorbital; pop, paraoccipital process; Pp, postparietal; Pr, prootic; Prf, prefrontal; Pt, pterygoid; ptc, postemporal canal; Q, quadrate; Qj, quadratojugal; qre, epipterygoid quadrate process; smf, septomaxillary foramen; Smx, septomaxilla; So, supraoccipital; Sq, squamosal; St, stapes; T, tabular; Vo, vomer. Scale bar: $10 \mathrm{~mm}$.

South Africa. The bearing stratum is presently interpreted to be part of the Balfour Formation, at the top of the Daptocephalus AZ (close to the Daptocephalus-Lystrosaurus AZ boundary). A cast of SAM-PK-K10596 in the Bayerische Staatssammlung für Paläontologie und historische Geologie in Munich is labelled as an advanced therocephalian from the base of the Lystrosaurus AZ on Groote Valley, Middelburg,
South Africa. In an accompanying note dated 24 August 1978, Dr J. Hopson stated that it represents 'a primitive cynodont close to Cynosaurus and Galesaurus'. Kemp (1972) figured and succinctly described another cast of this same specimen, housed at UCMZ, that he identified as 'a possible whaitsiid-cynodont'.

CGP GHG141 is an undeformed partial skull, lacking the tip and the left portion of the snout (Figs 5-7). 

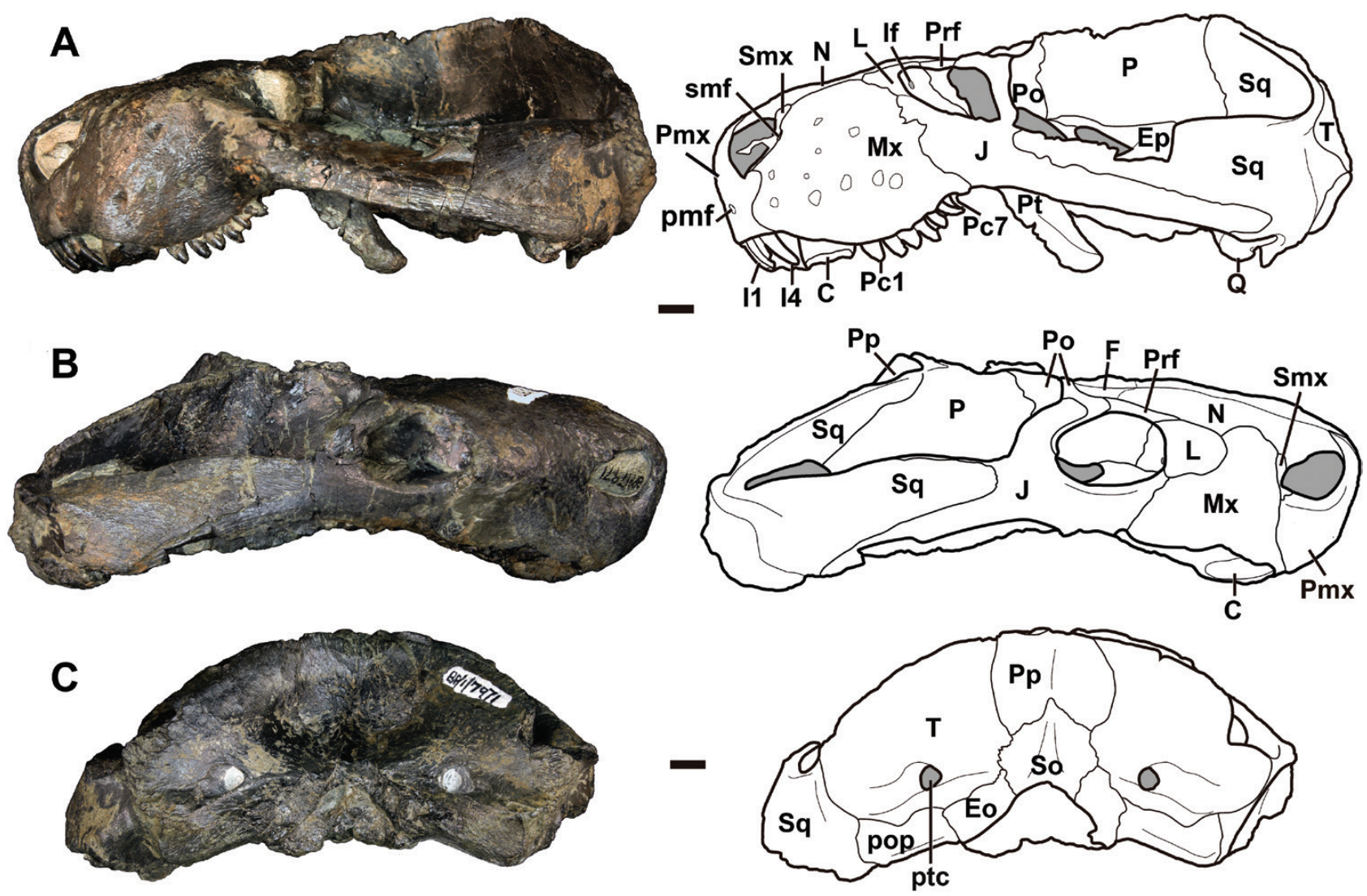

Figure 2. BP/1/7971. Skull in left lateral view (A), right lateral view (B) and occipital view (C). Abbreviations: C, canine; Eo, exoccipital; Ep, epipterygoid; F, frontal; I, incisive; J, jugal; L, lacrimal; lf, lacrimal foramen; Mx, maxilla; N, nasal; P, parietal; Pc, postcanine; pmf, premaxillary foramen; Pmx, premaxilla; Po, postorbital; pop, paraoccipital process; Pp, postparietal; Prf, prefrontal; Pt, pterygoid; ptc, postemporal canal; Q, quadrate; smf, septomaxillary foramen; Smx, septomaxilla; So, supraoccipital; Sq, squamosal; T, tabular. Scale bars: $10 \mathrm{~mm}$.

The right zygomatic arch is incomplete and the left is damaged. The dentition is not preserved except for part of the roots of some teeth. The palate and braincase are relatively well preserved. The right lateral wall of the skull is beautifully preserved and the left side is covered by matrix. Sutures are clearly distinguishable.

First-hand examination of specimens and published literature on basal cynodonts was considered for comparisons: Abdalodon diastematicus Kammerer, 2016 (SAM-PK-K10138; Botha-Brink \& Abdala, 2008; Kammerer, 2016); Charassognathus gracilis Botha et al., 2007 (SAM-PK-K10369; Botha et al., 2007); Cynosaurus suppostus Owen, 1876 (AM 4947, NHMUK R1718, SAM-PK-4333, BP/1/3926 and BP/1/4469; Haughton, 1918; Brink, 1965; van den Brandt \& Abdala, 2018), Dvinia prima Amalitzky, 1922 (PIN 2005/2465; Tatarinov, 1968; Ivakhnenko, 2013), Galesaurus planiceps Owen, 1860 (AMNH 2223, BP/1/4602, BP/1/4714, BP/1/5064, RC 845, NMQR 135, NMQR 860, NMQR 1451, NMQR 3340, NMQR 3542,
SAM-PK-K1119, SAM-PK-K9956, SAM-PK-K10465, SAM-PK-K10468, TM 24, TM 83 and UMZC T819b; Jasinoski \& Abdala, 2017), Nanictosaurus kitchingi Broom, 1936 (TM 279 and RC47; van Heerden, 1976; van Heerden \& Rubidge, 1990), Platycraniellus elegans van Hoepen, 1916 (TM 25 and NMQR 1633; Abdala, 2007), Procynosuchus delaharpeae Broom, 1937 (BP/1/226, BP/1/591, BP/1/1545, BP/1/2600, BP/1/3748, NHMUK PV R 37054, RC 5, RC 12, RC 87, RC 92, SAM-PK-K5819 and UMZC T.810; Brink, 1963; Anderson, 1968; Kemp, 1979), Progalesaurus lootsbergensis Sidor \& Smith, 2004 (SAM-PK-K9954; Sidor \& Smith 2004) and Thrinaxodon liorhinus Seeley, 1894 (AMNH 4283, BP/1/1737, BP/1/4280, BP/1/5208, BP/1/5905, BP/1/7199, NHMUK R511, NHMUK R3731, NHMUK R5480, NHMUK R511a, NMQR 810, NMQR 812, SAM-PK-K10607, TM 167, TM 180, UMZC T815, UCMP 40466, UCMP 42865 and UCMP 42866; Estes, 1961; Fourie, 1974; Jasinoski et al., 2015). 


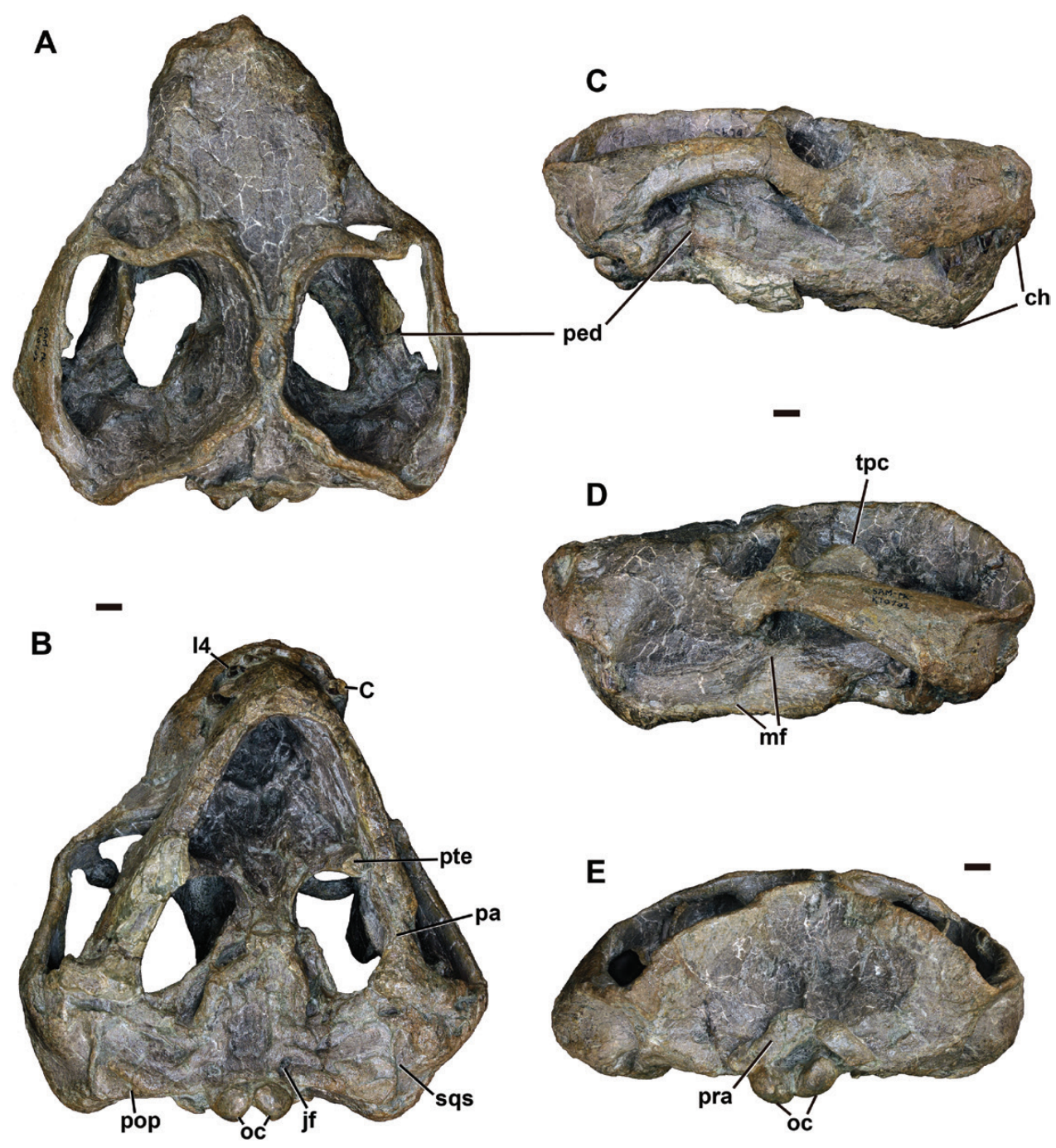

Figure 3. SAM-PK-K10702. Skull and articulated lower jaw in dorsal view (A), ventral view (B), right lateral view (C), left lateral view (D) and occipital view (E). Abbreviations: C, canine; ch, symphyseal chin; I, incisive; jf, jugular foramen; mf, masseteric fossa; oc, occipital condyles; pa, prearticular; ped, posterior extension of the dentary; pop, paroccipital process; pra, proatlas; pte, pterygoid process; sqs, squamosal sulcus; tpc, tip of the coronoid process. Scale bars: $10 \mathrm{~mm}$.

\section{PHYLOGENETIC ANALYSIS}

We compiled a data matrix of 84 craniodental characters and 26 taxa: one gorgonopsid, seven therocephalians and 18 cynodonts. The matrix is modified from Abdala (2007) and includes characters proposed by Kammerer (2016) and by Huttenlocker et al. (2011) (see Appendix files). We used the computer program TNT (tree analysis using new technology) v.1.5 to search for the most parsimonious trees (Goloboff et al., 2008; Goloboff $\&$ Catalano, 2016). The search strategy considered all characters having equal weight, multistate characters with adjacency of states as additives (Lipscomb, 1992) and collapsing rule 1 (Coddington \& Scharff, 1994), which collapses branches with ambiguous support. We performed heuristic searches of 100 random addition sequences, keeping $\leq 100$ trees in memory (hold command).

\section{RESULTS}

THERAPSIDA BROOM, 1905

Cynodontia Owen, 1861

EPICYNODONTIA HOPSON \& KITCHING, 2001

\section{VETUSODON ELIKHULU GEN. ET SP. NOV.} Type and only species, Vetusodon elikhulu

Etymology: From Latin adjective vetus, 'old, ancient'

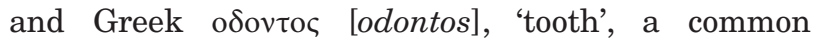



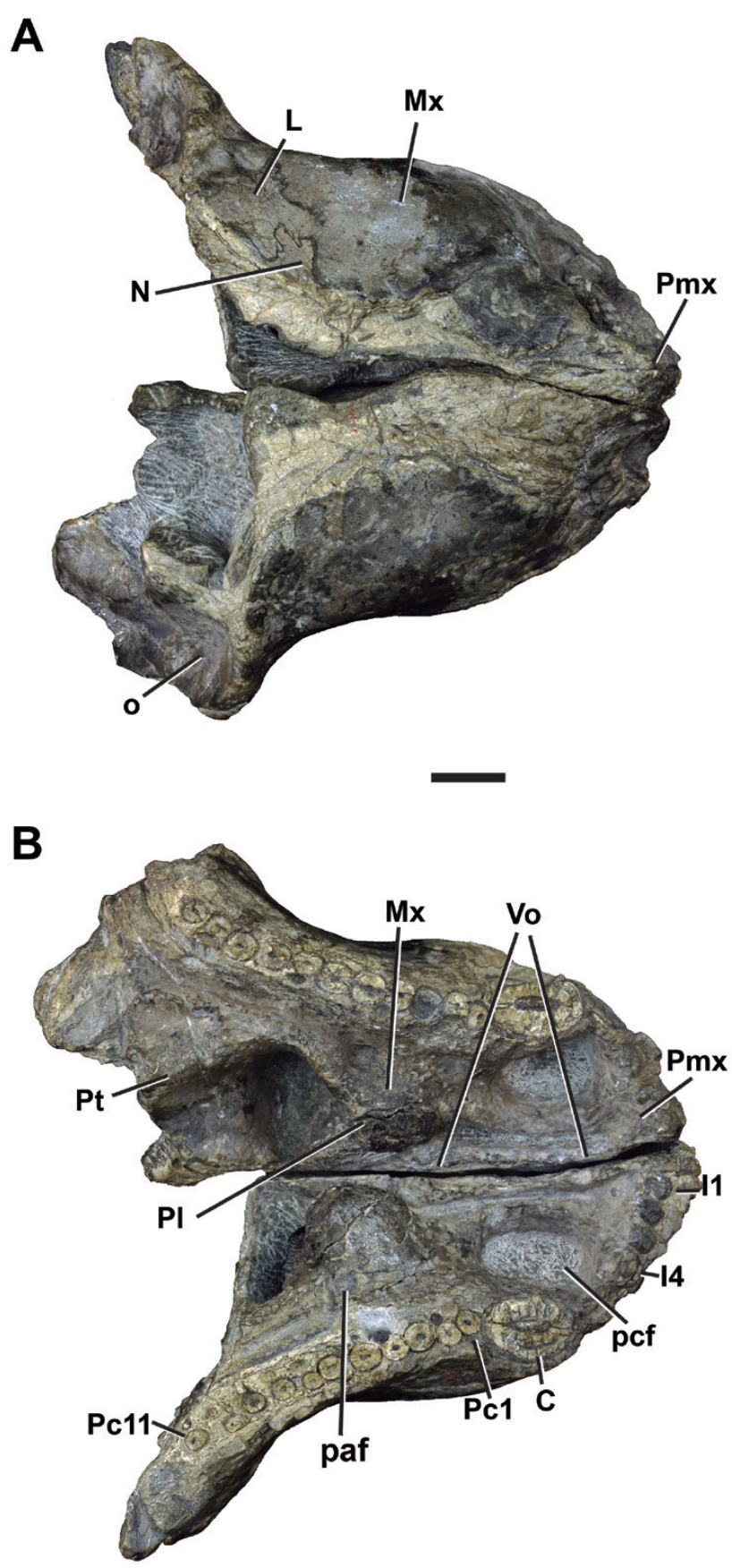

Figure 4. SAM-PK-K10596. Snout in dorsal view (A) and ventral view (B). Abbreviations: $C$, canine; I, incisive; L, lacrimal; Mx, maxilla; N, nasal; o, orbit; paf, palatal foramen; Pc, postcanine; pcf, paracanine fossa; Pl, palatine; Pmx, premaxilla; Pt, pterygoid; Vo, vomer. Scale bar: $10 \mathrm{~mm}$.

ending for cynodont genera, in reference to the late Permian age of the known specimens. The species name elikhulu, meaning 'large' in Zulu, a widespread language in the area where the holotype was found, refers to the relative large size of the specimens.
Holotype: BP/1/7971, almost complete skull (Figs 1, 2).

Referred specimens: SAM-PK-K10702, complete skull and articulated lower jaw. CGP GHG141, partial skull. SAM-PK-K10596, pre-orbital region of a skull.

\section{LSID: zoobank.org:act:055D0DAA-150F-489B-844D-} 1C709B894636

Diagnosis: A large Permian cynodont, with a basal skull length of $\geq 18 \mathrm{~cm}$. The skull is almost as wide as long; the snout is short and exceptionally wide. As in several eucynodonts, the dentary extends far posteriorly, with only a short separation from the craniomandibular joint. As is probably the case in Cynosaurus suppostus, the coronoid process of the mandible is very tall, reaching the level of the dorsal portion of the orbit. The dentary is low, with a tall symphysis, producing an anterodorsally directed chin. Autapomorphies of the new cynodont are as follows: a short, incomplete secondary osseous palate, with the posterior portion of the maxilla ventrally overlying the vomer and partly covering it; ventromedial palatal ridge of the premaxilla is slightly projected medially; a robust quadrate; the dorsal posterior projection of the postorbital ends anterior to the parietal foramen and does not form a central sagittal crest; a very short sagittal crest is posterior to the parietal foramen; and the relatively small postcanines bear a single conical cusp that is slightly oriented backwards.

Provenance: The holotype(BP/1/7971) was found during an expedition led by Dr B. Rubidge in 2010 . The specimen is from a mudstone bed below a coarse-grained sandstone of the Balfour Formation and is from the Daptocephalus AZ. The specimen was recovered downstream from the causeway bridge crossing the Injisuthi River, close to the Enyezane locality, KwaZulu-Natal Province, South Africa.

CGP GHG141 was collected in the Normandien Formation (= Balfour Formation) at Thaba Nchu, South Africa on 26 March 1985. This specimen was found associated with the specimens CGP GHG140 and CGP GHG142, identified in the CGP catalogue as Dicynodon lacerticeps Owen, 1845. CGP GHG140 was later assigned to Daptocephalus leoniceps (Owen, 1876) by Kammerer et al. (2011).

SAM-PK-K10702 was recovered from a level $\sim 20 \mathrm{~m}$ below the Permo-Triassic boundary (Daptocephalus AZ), in the Elandsberg Member of the Balfour Formation on Ripplemead Farm, near Nieu Bethesda, South Africa during an expedition led by Dr R. Smith. At the same level, and $<1 \mathrm{~m}$ away, a Lystrosaurus maccaigi (Seeley, 1898) specimen, including cranial and postcranial remains, was excavated (field number RS 440, SAM-PK-K10690). 

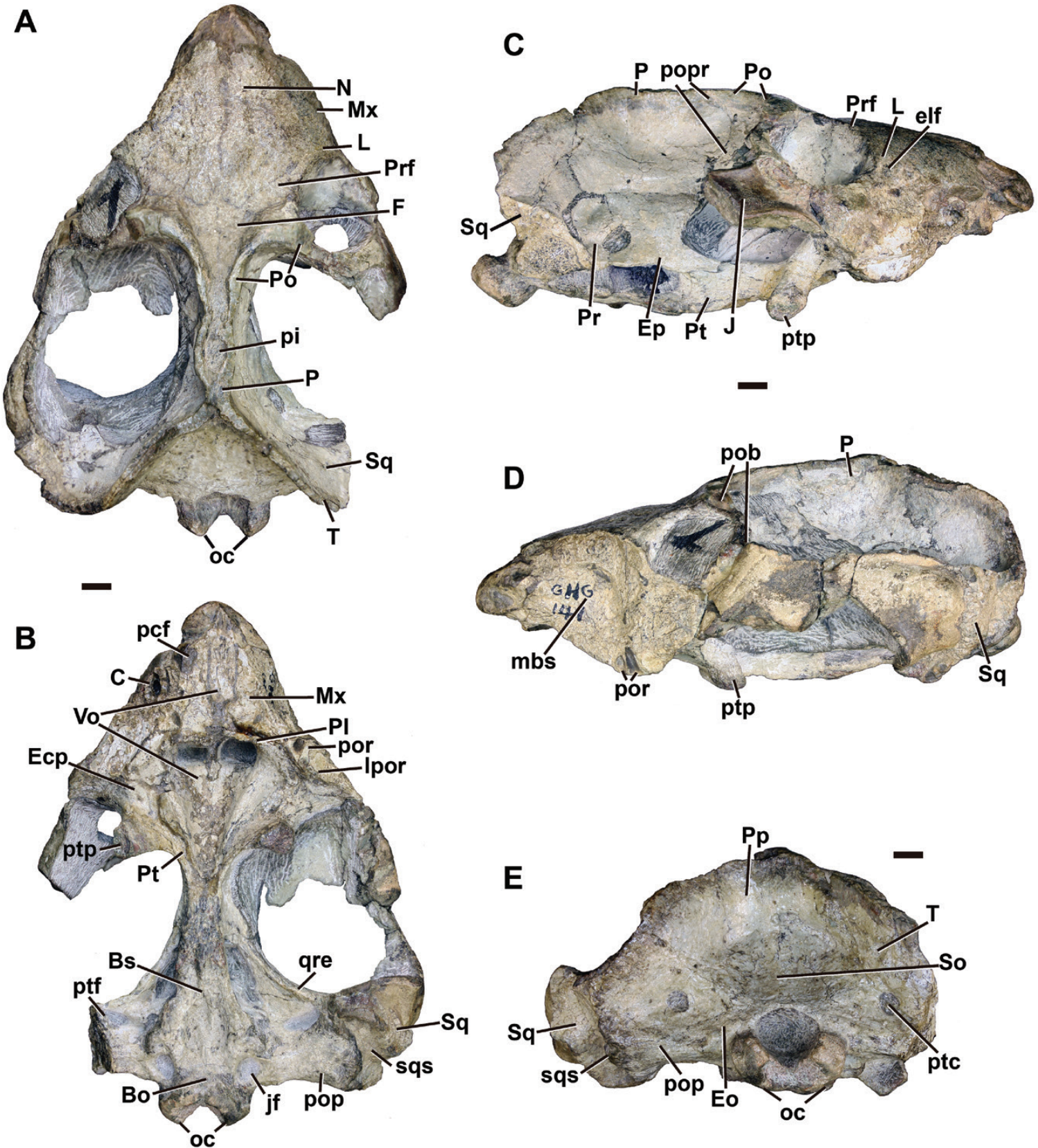

Figure 5. CGP GHG1441. Partial skull in dorsal view (A), ventral view (B), right lateral view (C), left lateral view (D) and occipital view (E). Abbreviations: Bo, basioccipital; Bs, basisphenoid; C, canine; Ecp, ectopterygoid; elf, external lacrimal foramen; Eo, exoccipital; Ep, epipterygoid; F, frontal; J, jugal; jf, jugular foramen; L, lacrimal; lpor, last postcanine root; mbs, maxilla broken surface; Mx, maxilla; N, nasal; oc, occipital condyles; P, parietal; pcf, paracanine fossa; pi, pineal foramen; Pl, palatine; Po, postorbital; pob, postorbital bar; pop, paraoccipital process; popr, postorbital processes; por, postcanine root; Pp, postparietal; Pr, prootic; Prf, prefrontal; Pt, pterygoid; ptc, postemporal canal; ptf, pterygoparaoccipital foramen; ptp, pterygoid process; qre, epipterygoid quadrate process; So, supraoccipital; Sq, squamosal; sqs, squamosal sulcus; T, tabular; Vo, vomer. Scale bars: $10 \mathrm{~mm}$.

SAM-PK-K10596 was found in the Balfour Formation at Groote Valley 133, Grootvlei, Middleburg, South Africa by Dr Crompton on a 1958/1959 expedition. The specimen is currently considered to come from the top of the Daptocephalus AZ, close to the DaptocephalusLystrosaurus AZ boundary. A plaster cast of SAMPK-K10596 is kept at the University Museum of Zoology, Cambridge, UK identified with the number 

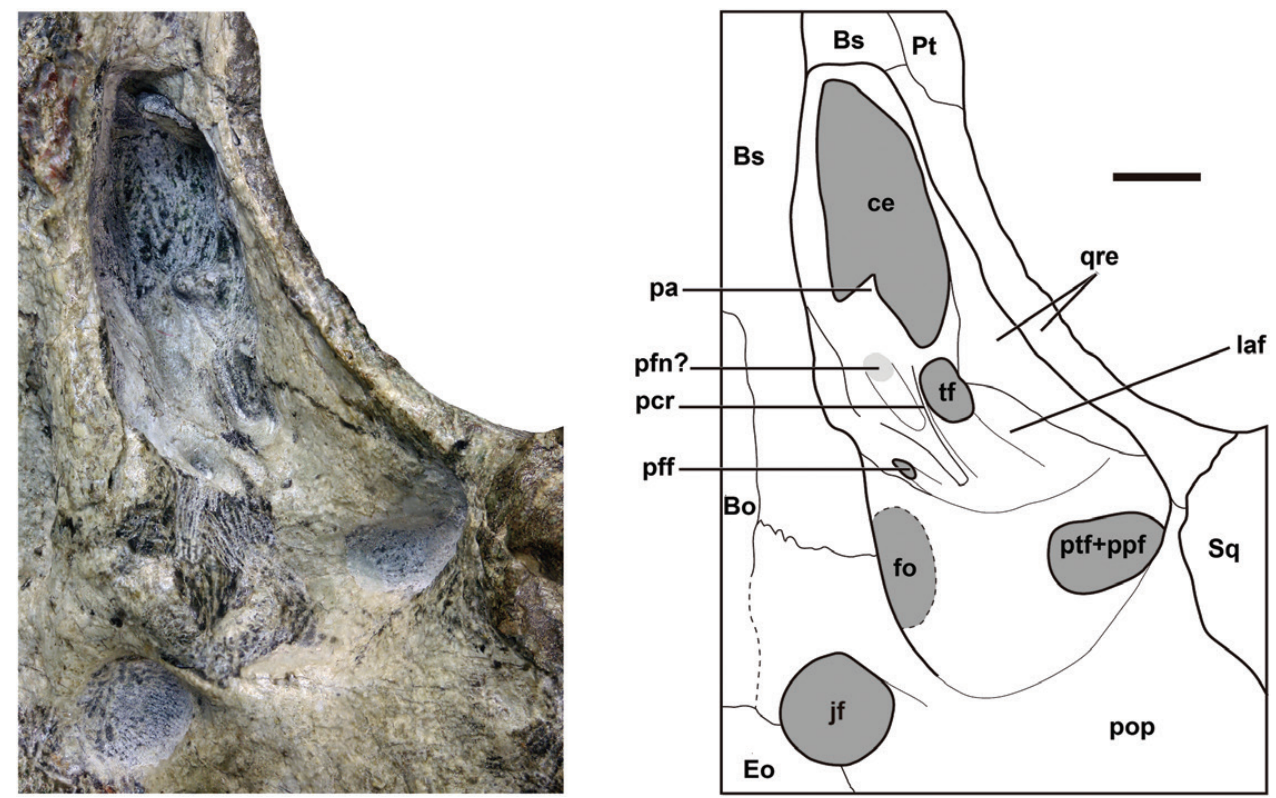

Figure 6. CGP GHG141. Ventral view of the basicranium with detail of the cavum epiptericum. Abbreviations: Bo, basioccipital; Bs, basisphenoid; ce, cavum epiptericum; Eo, exoccipital; fo, fenestra ovalis; jf, jugular foramen; laf, lateral flange; pa, pila antotica; pcr, prootic crest, pff, primary facial foramen; pfn, abducens or palatine branch of the facial nerve; pop, paraoccipital process; Pt, pterygoid; ptf+ppf, postemporal fenestra + pterygoparaoccipital foramen; qre, epipterygoid quadrate ramus; Sq, squamosal; tf, trigeminal foramen. Scale bar: $10 \mathrm{~mm}$.

UCMZ T980 in the figure epigraph (Kemp, 1972: fig. 19 plate 1) and as UCMZ T950 in the main text (Kemp, 1972: 34). Another cast of this specimen is at the Bayerische Staatssammlung für Paläontologie und historische Geologie, Munich (F. Abdala, pers. obs.).

Precise coordinates of the localities are available from curators of the various collections.

\section{DESCRIPTION}

The following description is an account of the morphological traits recognized in the different specimens of Vetusodon elikhulu known to date. For clarity, the specimen numbers are provided only when necessary.

\section{SKULL}

The broad and relatively low skull is triangular in dorsal view (Figs 1A, 3A) with the maximal cranial width across the posterior portion of the large, ovoid temporal fenestra. The skull is only slightly longer than wide, with a width-to-length ratio of $88 \%$ in $\mathrm{BP} / 1 / 7971$ and $93.5 \%$ in SAM-PK-K10702 (Table 1). The temporal region is relatively long, representing $\sim 60 \%$ of the skull length, whereas the snout and the orbital region constitute $40 \%$ of the total length of the skull (Table 1). The snout is noticeably short and wide, its length being $16-21 \%$ of the total skull length (Table 1; Figs $1 \mathrm{~A}, 3 \mathrm{~A}, 4 \mathrm{~A})$. The tip of the snout is pointed, projecting anteriorly beyond the incisors, and high in lateral view (Fig. 2A, B). The orbits and the external nares are anterolaterally oriented.

\section{Snout and orbital region}

The anteriormost portion of the snout is formed by the premaxilla and the nasals, with a robust internarial process of the premaxilla oriented somewhat anteriorly (Fig. 2A, B). This process extends posterodorsally as a robust structure halfway along the length of the nasal opening. A relatively large anterior premaxillary foramen is observed between incisor (I) 1 and I2 on the left side of BP/1/7971 approximately one-third of the height of the premaxilla. This foramen could not be identified in SAM-PK-K10702, the only other specimen preserving this region. Posteriorly, the premaxilla is very robust and lacks a distinct extranasal process (Fig. 2A). The premaxilla extends up to the posterior margin of the alveolus of the last incisor in lateral view.

A well-preserved left septomaxilla is present in BP/1/7971(Figs 1A, 2A, B) and SAM-PK-K10596, whereas it is damaged and not clear in SAM-PK-K10702. The septomaxilla is robust, with a relatively broad but short facial process that extends between the nasal and maxilla for $\sim 6.5 \mathrm{~mm}$. The intranarial process is gracile, horizontal and extends anteriorly for $\sim 82 \%$ of 
A
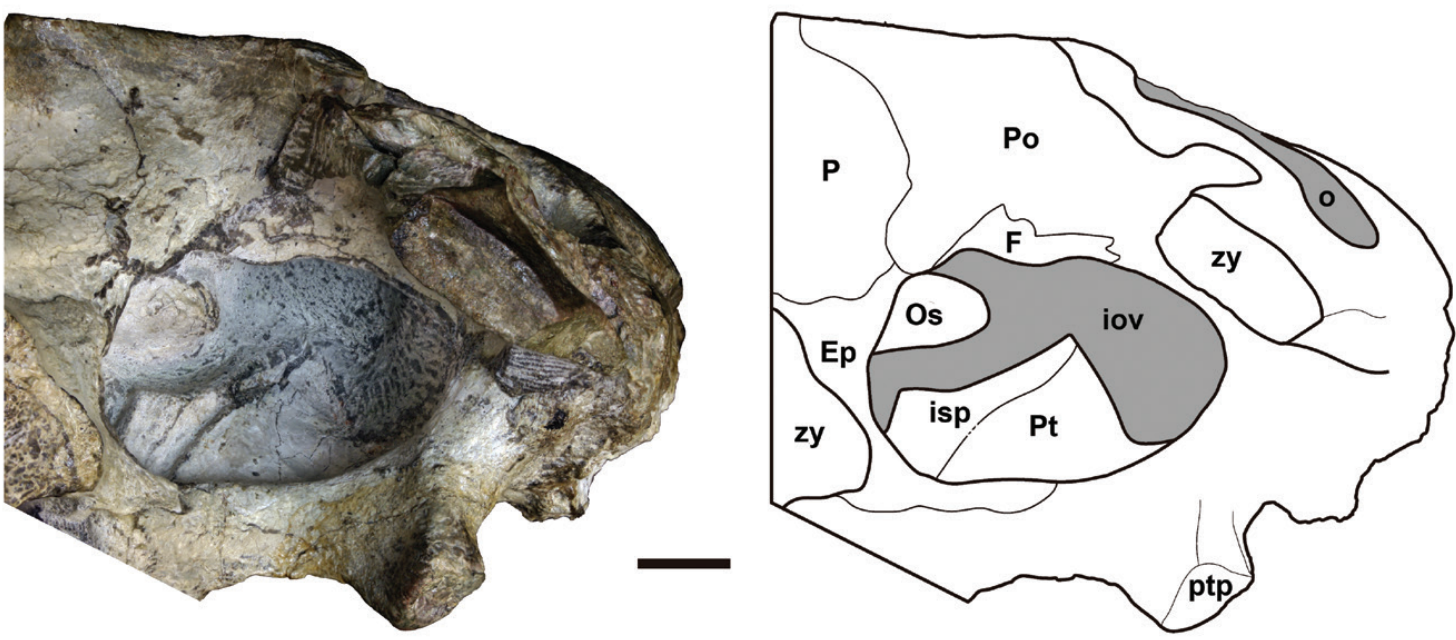

B
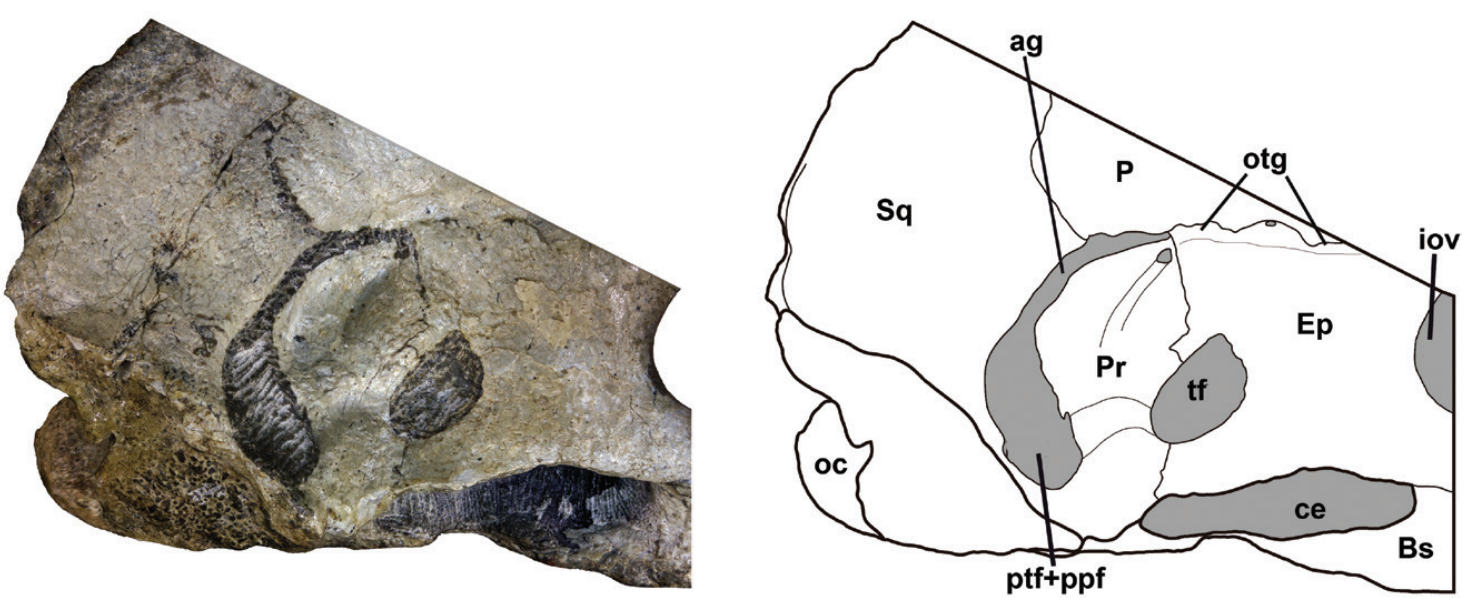

Figure 7. CGP GHG141. A, posterolateral view of the interorbital region. B, lateral view of the right lateral wall of the skull. Abbreviations: ag, ascending groove; Bs, basisphenoid; ce, cavum epiptericum; Ep, epipterygoid; F, frontal; iov, interorbital vacuity; isp, interorbital septum; o, orbit; oc, occipital condyle; Os, orbitosphenoid; otg, orbitotemporal groove; P, parietal; ptf+ppf, postemporal fenestra + pterygoparaoccipital foramen; Po, postorbital; Pr, prootic; Pt, pterygoid; ptp, pterygoid process; tf, trigeminal foramen; zy, zygoma. Scale bars: $10 \mathrm{~mm}$.

the length of the external naris (Fig. 2A). The medial lamina has only a short anterior contact with the premaxilla and posteriorly has a longer contact with the maxilla, constituting $75 \%$ of the ventral border of the nasal opening. A septomaxillary foramen is present between the septomaxilla and the maxilla, at the level of the intranarial process (Fig. 2A).

The maxilla is large, extending over most of the lateral surface of the snout and emarginated at the level of the canine. The ventral margin of the maxilla is strongly convex in lateral aspect (Figs 2A, 3C, D). Posteroventrally, the maxilla tapers into an acute zygomatic process that extends less than halfway across the mid-length of the orbit. The lateral surface of the maxilla has several, relatively large $(2-3 \mathrm{~mm}$ in diameter) foramina arranged in two longitudinal series. These are most clearly seen on the left side of BP/1/7971 (Fig. 2A). The lower series, relatively far from the alveolar margin, is at the level where the infraorbital foramen is usually positioned. The second series is between the levels of the base of the external naris and of the septomaxillary foramen. Additional small foramina pierce the external surface of the maxilla. There is no identifiable infraorbital foramen. 
Table 1. Measurements of specimens of Vetusodon elikhulu (in millimetres)

\begin{tabular}{lllll}
\hline & BP/1/7971 & SAM-PK- K10702 & CGP GHG141 & SAM-PK-K10596 \\
\hline BSL & $\sim 180$ & 184 & $\sim 179$ & 76.4 \\
MUL & 67.1 & 72.3 & $\sim 66$ & 58.3 \\
OL & 36.6 & 32.1 & 50.9 & 55.8 \\
TEL & 40.2 & 59.1 & \\
PAL & 53.1 & 61.6 & \\
SW & 140.9 & 172.1 & \\
IO & 53.0 & 61.9 & \\
OD & 28.5 & 29.5 & \\
BGW & 15.4 & 23.2 & \\
MTO & 81.3 & 92.9 & \\
BB & 43.8 & 50.8 & \\
OH & 64.4 & 77.8 & \\
OW & 98.0 & 111.4 & \\
ZH & 29.4 & 32.9 & \\
BW & 64.6 & 58.1 & \\
TP & 60.1 & 66.5 & \\
UP & 28.3 & & \\
SL & 27.0 & 29.0 & \\
MAL & & 143.9 & \\
DL & & 125.7 & \\
VRH & & 66.0 & \\
\hline & & & \\
\end{tabular}

Abbreviations: BB, basisphenoid-basioccipital length; BGW, basicranial girder width; BSL, basal skull length; BW, maxillary bicanine width; DL, dentary length; IO, interorbital distance; MAL, mandibular length; MTO, maximal length of the temporal opening; MUL, muzzle length; OD, orbital diameter; OH, occipital plate height; OL, orbital length; OW, occipital plate width; PAL, palate length; SL, stapes length; SW, maximum skull width; TEL, temporal region length; TP, width of the transverse process of the pterygoid; UP, upper postcanine tooth row length; VRH, vertical ramus of the dentary length; $\mathrm{ZH}$, maximal height of the zygomatic arch.

The convex (BP/1/7971; Fig. 2A, B) to flat (SAMPK-K 10702; Fig. 3C, D) dorsal surface of the snout is almost entirely formed by the very broad nasals, which extend from the anterior portion of the snout to the middle portion of the orbits (Fig. 1A). The nasals constitute the dorsal margin of the external naris, anterior to the facial process of the septomaxilla. As clearly observed in CGP GHG141, the posterior margin of the nasals is M-shaped, with a short indentation for an anterior projection of the frontals (Fig. 5A). The nasal-frontal contact is less than half the length of the nasal-prefrontal one (Fig. 1A). A series of foramina are parallel to the internasal suture in CGP GHG141.

The frontals are very narrow and triangular, tapering from a broader anterior margin to a very acute posterior end. Dorsally, they are flat and rise posteriorly, partly forming the medial surface of the rising crest of the postorbitals, anterior to the pineal foramen (Fig. 1A). The frontal is excluded from the orbital margin by the prefrontal and the postorbital (Fig. 1A). In the posteroventral corner of the medial surface of the right orbit of CGP GHG141, a low portion of the frontal is exposed ventral to the postorbital (Fig. 7A).

The lacrimal is a relatively large element, subquadrangular in dorsal view (Fig. 1A). It forms the anterior one-third of the vertical, medial wall of the orbit, where a laterally placed and relatively small lacrimal foramen is present (Figs 1A, 2A). A large foramen on the lateral surface of the lacrimal, as observed on the right side of CGP GHG141, might represent the external opening of the lacrimal foramen (Fig. 5C). This opening is clearly observed in SAM-PK-K10702 and SAM-PK-K10596. In SAMPK-K10596, this foramen is positioned in a deeply depressed area of the lacrimal bone.

The prefrontal is externally rectangular, having a short posteromedial contact with the frontal and a long contact with the nasal anteromedially (Fig. 1A). The prefrontal contribution to the medial rim of the orbit is as long as that of the lacrimal. Along with the pterygoid, the ventral margin of the inner orbital portion of the lacrimal forms the posteromedial floor of the orbit. Lateral to them, the jugal makes up the posterolateral floor of the orbit.

The raised postorbital contacts the prefrontal and frontal anteriorly and medially, respectively, producing a conspicuous step (Figs 3A, 5A) and a robust postorbital ramus that extends almost as far as the base of the postorbital bar. A relatively thin and flat ascending process of the jugal overlies the postorbital 
process of the postorbital and extends dorsally to almost the top of the postorbital bar.

The postorbital forms an elevated posteromedially directed ridge, medially walled by the frontal, and extends for approximately the anterior portion of the intertemporal region close to the level of the pineal foramen (Figs 1A, 3A, 5A). From that point, the ridge continues posteriorly, composed only by the parietal. Anterior to the pineal foramen, the right and left ridges converge, forming a deep sulcus between the crests (Fig. 1A). The posterior projection of the postorbital is relatively narrow, with a concave posterior margin, producing two processes in lateral view, a lobated and wide ventral one and an acute and narrow dorsal one (Fig. 2A). Two processes arising from the posterior margin of the postorbital are also documented in the basal cynodonts Cynosaurus, Galesaurus and Progalesaurus (Sidor \& Smith, 2004; Jasinoski \& Abdala, 2017; van den Brandt \& Abdala, 2018 ). The dorsal process contacts the parietal, whereas the ventral process is in contact with the epipterygoid, as clearly observed in CGP GHG141 (Fig. 7A).

\section{Zygoma and temporal region}

The zygomatic arch is dorsoventrally high, with the maximum height posteriorly, at the level of the craniomandibular joint (Figs 2A, B, 3C, D), and represents $\sim 45 \%$ (in $\mathrm{BP} / 1 / 7971$ ) and $\sim 42 \%$ (in SAM-PK-K10702) of the maximum height of the skull at the occipital plate. In ventral view, the zygomatic arch is thin and becomes slightly thinner at the level of the quadrate. In dorsal view, the arch is markedly thick posteriorly (Figs 1A, $3 \mathrm{~A}$ ), and its posterodorsal surface is flat. In lateral view, the ventral margin of the zygomatic arch is concave (Fig. 3C, D). On the posterior region of the zygomatic arch, on top of the squamosal sulcus, is a posterolaterally oriented crest that is continuous with the occipital crest (Fig. 2A).

The jugal forms most of the zygomatic arch, extending posteriorly up to the level of the quadrate (Fig. 2A). The anteriorly projecting squamosal covers most of the lateral side of the jugal, with only a very thin exposure of the jugal on the dorsal side of the squamosal (Fig. 2B).

The large pineal foramen is positioned approximately halfway along the temporal region. In BP/1/7971 it is almost circular, whereas in CGP GHG141 and SAMPK-K10702 it is ovoid (Figs 1A, 3A, 5A). As a result of the particular construction of the intertemporal region, the sagittal crest is broad and extremely short, bifurcating into the occipital crests posterior to the pineal foramen (Figs 1A, 3A, 5A).

\section{Palate}

The osseous secondary palate is short and incomplete, with the two sides comprising premaxilla, maxilla and palatine not meeting along the midline (Figs 1B, 4B, 5B). It extends to approximately the third postcanine in $\mathrm{BP} / 1 / 7971$, and the posterior palatal platform behind the paracanine fossa is about the same length as the fossa (Fig. 1B). In SAM-PK-K10596, the palate extends up to the level of the sixth postcanine, and the posterior palatal platform is longer than the length of the paracanine fossa (Fig. 4B). However, in comparison with the upper tooth row length (measured from the anterior alveolar margin of the incisors to the last postcanine), the palate of SAM-PK-K10596 is proportionally shorter, making up only $67 \%$ of the upper dentition length, whereas in $\mathrm{BP} / 1 / 7971$ it represents $85 \%$.

The premaxilla produces a prominent robust projection that extends posteroventrally beyond the alveolar margin immediately behind the first incisor. A foramen is present lateral to this projection, on the left side of BP/1/7971 (Fig. 1B) and SAM-PK-K10596 (this area is either not preserved or covered by matrix on the right side of these specimens). This foramen was also described for Thrinaxodon (Parrington, 1946; Fourie, 1974). The premaxilla has a long, welldeveloped medial process that contacts its counter element. This process produces two small projections: a short, gracile and acuminated medial projection, and a long, more robust lateral one. These projections contact the triangular anterior portion of the vomer, enclosing an anteroposteriorly elongated foramen (Fig. 1B). A much smaller opening in a similar position was illustrated for Procynosuchus as the sphenopalatine foramen (Kemp, 1979: fig. 2) and also seems to be present in Cynosaurus (van den Brandt \& Abdala, 2018: fig. 5B). The maxillary process of the premaxilla is very robust and bears posteriorly an incipient ventromedially projecting crest. This process contacts the maxilla at the same level as the medial process contacts the vomer, which is approximately at the midpoint of the canine alveolus (Fig. 1B).

A long, narrow and posteriorly incomplete incisive foramen is bordered medially by the medial process of the premaxilla and the vomer, and laterally by the maxillary process of the premaxilla and the maxilla (Fig. 1B). The large and rounded paracanine fossa is positioned anteromedially to the canine and is limited anteriorly and medially by the premaxilla and posteriorly and laterally by the maxilla (Figs 1B, 4B).

The maxilla forms most of the short and incomplete secondary palate, with only minor participation of the palatine, which is restricted to the posterior portion of the palate (Fig. 1B). The palatal process of the maxilla partly covers the vomer in ventral view. 
On the left side of $\mathrm{BP} / 1 / 7971$, the medial part of the suture between the maxilla and palatine is straight, whereas on the right it is serrated. The suture between the palatal process of the maxilla and palatine is at the level of the posterior margin of the postcanine (PC) 2 in BP/1/7971 and CGP GHG141 and of PC5 in SAM-PK-K10596 (Figs 1B, 4B). A large, rounded palatal foramen is present on the suture between these bones, which except for the posterior margin, is rimmed by the maxilla. This foramen is extensively recorded in basal cynodonts (e.g. Parrington, 1946; Fourie, 1974; Kemp, 1979; Hopson \& Kitching, 2001; Abdala \& Allinson, 2005; Ivakhnenko, 2013; van den Brandt \& Abdala, 2018), although it was not reported in Platycraniellus (see Abdala, 2007). The foramen appears to be comparatively larger in Vetusodon.

The quadrangular ectopterygoid is bounded by the maxilla, palatine and pterygoid, and a large ectopterygoid foramen is positioned near the posterior margin of the bone (Fig. 1B). In BP/1/7971 and CGP GHG141, the ectopterygoid is medial and posterior to the last postcanine.

The palatine extends posteriorly as a well-developed pterygopalatine ridge and continues approximately to the level of the base of the very long pterygoid process. Here, the pterygopalatine ridge ends in a low, rounded boss in BP/1/7971 and SAM-PK-K10702 but not in CGP GHG141. Posteriorly, a narrow crest formed by the pterygoid continues up to the end of the primary palate (Fig. 1B). Lateral to the pterygopalatine ridge, the ventral surface of the pterygoid is concave. The pterygoid process is posteroventrally directed at an angle of $\sim 45^{\circ}$ relative to the horizontal in $\mathrm{BP} / 1 / 7971$ and CGP GHG141(Figs 2A, 5C, D). In SAM-PK-K10702, the process is more ventrally oriented, with an angle of $\sim 60^{\circ}$ relative to the horizontal. It is triangular in crosssection and has a flat lateral surface. In BP/1/7971, a broad and poorly defined crest runs diagonally (from dorsal to ventral) on the ventral third of the lateral surface of the pterygoid process (Fig. 2A).

The vomer forms a flat plate anteriorly, with an acute triangular anterior projection and no traces of a midline suture (Fig. 1B), although there is a groove along the midline of this plate. Posterior to the end of the secondary palate, the vomer continues as a thin, vertical bone that becomes a strong ridge along the midline. This ridge, which becomes progressively lower posteriorly, extends to the posterior end of the choanal trough. On both sides of the choanal medial ridge, the ventral surface of the primary palate is concave.

The elongated triangular choanal trough comprises $27-28 \%$ of basal skull length in BP/1/7971, CGP GHG141 and SAM-PK-K10702, extending posteriorly to approximately halfway along the temporal region (Figs 1B, 3B, 5B). It is roofed by the expanded portion of the vomer anteriorly (approximately half the length) and by the pterygoids posteriorly, which also form the almost-vertical lateral walls. Anterior to the pterygoid, the primary palate lateral wall is formed by the palatine, which also forms a small part of the anterolateral corner of the ventral surface. The vomer curves dorsally just behind the internal openings of the nasopharyngeal passage. Posteriorly, the choanal trough ends very close to the basicranium, which implies a short, nearly absent basicranial girder. There is no interpterygoid vacuity (Figs 1B, 3B, 5B). In basal cynodonts, this vacuity is a well-developed opening in Procynosuchus (Kemp, 1979; Abdala \& Allinson, 2005) and Dvinia (Ivakhnenko, 2013), but it is small in Platycraniellus (Abdala, 2007) and juvenile individuals of Thrinaxodon (Estes, 1961; Jasinoski et al., 2015). The vacuity is absent in Cynosaurus, Galesaurus and Progalesaurus (Sidor \& Smith, 2004; Jasinoski \& Abdala, 2017; van den Brandt \& Abdala, 2018). Kammerer (2016) mentioned the absence of this opening in Abdalodon, but additional preparation of the area in the type and only specimen of the taxon confirm the presence of the opening as originally stated by Botha-Brink \& Abdala (2008).

\section{Lateral wall of the skull and interorbital region}

A large, ellipsoid interorbital vacuity is well preserved in CGP GHG141 (Fig. 7A). The orbitosphenoid is observed on the dorsal portion of the vacuity, and an incomplete interorbital septum is present ventrally (Fig. 7A).

The orbitosphenoid is a tubular, hemicylindrical, thin bone, incompletely preserved and located in the dorsoposterior corner of the interorbital vacuity. The bone seems to have a ventral opening in its posterior region. A small space is present between the ventral margin of the orbitosphenoid and the dorsal margin of the interorbital septum (Fig. 7A). This septum appears to be formed by two bones separated by a suture extending diagonally from the base to the top. The anteroventral bone of the septum is the pterygoid, which has an extensive vertical representation, whereas the thin posterodorsal bone is interpreted as a strip of the parasphenoid (Fig. 7A). Tubular orbitosphenoids with variable longitudinal extension were recently recognized in several basal cynodonts, such as Procynosuchus, Cynosaurus, Galesaurus and Thrinaxodon, but there is no evidence of a septum in the interorbital vacuity (Benoit et al., 2017). An ossified septum in the interorbital vacuity is rarely preserved in Permo-Triassic theriodonts, but it is known in some therocephalians, such as Theriognathus (Kemp, 1972; Huttenlocker \& Abdala, 2016) and Microgomphodon (Abdala et al., 2014).

The epipterygoid is anteroposteriorly expanded both dorsally and ventrally (Fig. 7B). The dorsal 
margin of the epipterygoid is approximately straight and horizontal. Anterodorsally, the bone contacts the ventral projection of the postorbital and anteriorly overlies the dorsal surface of the pterygoid (Fig. 7A). A large, oval foramen for the trigeminal nerve is present between the epipterygoid and the prootic. The epipterygoid forms the anterior, dorsal and ventral rims of this foramen, and the prootic makes up its posterior margin (Fig. 7B).

In lateral view, the prootic is relatively narrow, as tall as and approximately half of the length of the epipterygoid (Fig. 7B). Dorsally, it contacts only the posteriormost ventral margin of the parietal. There is a deep external dorsal ascending groove (Rougier et al., 1992) filled by matrix between the prootic anteriorly and the squamosal/parietal posterior and dorsally (Fig. 7B). The anterior lamina of the prootic, above the level of the trigeminal opening, is deeply concave. A well-defined groove within this concavity leads to a small foramen on the anterodorsal corner of the prootic, close to its contact with the parietal and the epipterygoid (Fig. 7B). Posterodorsally, the prootic contacts the squamosal. Ventral to this contact, a large pterygoparoccipital foramen is present between the two bones. A groove, walled by a distinct dorsal crest, runs through the prootic between the pterygoparoccipital foramen and the foramen for the trigeminal nerve (Fig. 7B).

The anterior opening of the post-temporal canal is not obvious because deformation and/or matrix prevents a clear view of this region, but it is interpreted to have opened close to the pterygoparoccipital foramen.

A well-developed orbitotemporal groove extends anteriorly from the pterygoparoccipital foramen into the interorbital vacuity (Fig. 7B). This groove is well marked between the dorsal margin of the prootic but less evident above the epipterygoid, where the parietal forms a longitudinal swollen area. Along this groove, there is a number of foramina (one in CGP GHG141 and two in $\mathrm{BP} / 1 / 7971$ ), which pierce the parietal dorsally, especially at the level of the posterior third of the epipterygoid.

\section{Basicranium}

The anterior portion of the basicranium in BP/1/7971 is relatively well preserved, but the posterior part is crushed, distorted laterally, and the occipital condyles are missing (Fig. 1B). In SAM-PK-K10702, the basicranium is complete but cracked, deformed and shows very poor preservation of the bone surface (Fig. 3B). CGP GHG141 has the best-preserved basicranium (Figs 5B, 6).

The basicranium is relatively narrow anteriorly and broad posteriorly. The basicranial girder is very short (Figs 1B, 3B, 5B). Its anterior half is formed by the basicranial ramus of the pterygoid and the posterior portion by the basipterygoid process of the parabasisphenoid. The short cultriform process projects between the basicranial rami of the pterygoids. The basipterygoid process is directed ventrally. A large carotid foramen, clearly observed on the lateral surface of the basicranial girder of BP/1/7971 (Fig. 1B), is rimmed by the basicranial ramus of the pterygoid and the basipterygoid process. The carotid foramen is also present in Procynosuchus, Thrinaxodon and Lumkuia (Parrington, 1946; Fourie, 1974; Kemp, 1979; Hopson \& Kitching, 2001), but was not observed in Platycraniellus and Cynosaurus (Abdala, 2007; Van den Brandt \& Abdala, 2018). In Galesaurus, this foramen was not described (e.g. Boonstra, 1935; Haughton, 1924), but it was scored as present in phylogenetic analyses (Hopson \& Kitching, 2001; Abdala, 2007), whereas in Progalesaurus it was not observed, but the area of placement of the foramen was interpreted as covered by sediment (Sidor \& Smith, 2004: 543).

The rectangular basioccipital extends anteriorly into the para-basisphenoid, producing an inverted $\mathrm{U}$-shaped contact between these bones in ventral view (Fig. 1B). In BP/1/7971 and SAM-PK-K10702, a prominent posteriorly widening ridge extends along the midline of the para-basisphenoid and the basioccipital. Depressed areas are bordered medially by the midline ridge and laterally by inflated lateral margins of the para-basisphenoid. In CGP GHG141, these structures are less conspicuous. In this specimen, the crest of the para-basisphenoid bifurcates on the basioccipital, defining a long, central depressed oval area (Fig. 5B). Posteriorly, these two crests reunite into a broad, low crest.

Two pairs of foramina, a small anterior and a larger posterior one, are present on the oval, depressed anterior portion of the basioccipital in CGP GHG141. A third pair of foramina is present further posteriorly, approximately halfway along the bone.

In ventral view, the para-basisphenoid ala forms the anteromedial margin of the fenestra ovalis, and its posteromedial margin is rimmed by the medial projection of the paroccipital process, with the result that the basioccipital does not participate in the margin of the fenestra ovalis (Fig. 6).

Anterior to the fenestra ovalis is a well-defined anteromedially directed groove leading to a foramen on the lateral wall of the braincase. This foramen is interpreted as the primary facial foramen (Fig. 6). Anterior to this groove and foramen, a second groove leads to a depressed oval area anteromedial to the primary facial foramen. This depression coincides with the expected position of the foramen for the abducens or palatine branch of the facial nerve, described in Thrinaxodon (Parrington, 1946) but, as in Platycraniellus (Abdala, 2007), this opening 
is apparently not present. A strong crest is present between the aforementioned grooves and meets the anterior end of the prootic crest. This crest is sharp and forms the medial border of a broad sulcus leading to the trigeminal foramen (Fig. 6). A prootic crest, close to the primary facial foramen, was also described in Platycraniellus (Abdala, 2007) and in the traversodontid cynodont Exaeretodon riograndensis, where the crest was interrupted by a notch (Abdala et al., 2002). Anteriorly, the trigeminal foramen is separated from the ventral opening of the cavum epiptericum by a strip of bone.

The jugular foramen is enclosed by the paroccipital process, except for its posterior margin, which is formed by the exoccipital (Fig. 6). This foramen is positioned far behind the fenestra ovalis, and it is longitudinally aligned with the fenestra ovalis and the occipital condyle, which is mainly formed by the exoccipital.

\section{Stapes}

The left stapes of BP/1/7971 is relatively well preserved and close to its original position (Fig. 1B). However, it has been dorsally compressed against the skull; the anterior crura is fractured, and the lateral platform is rotated relative to the medial one. Both stapes are poorly preserved in SAM-PK-K10702, and only the medial portion of the right one is preserved in situ in the fenestra ovalis. The left stapes is complete but fractured.

The stapes is a long, bicrurated bone, with horizontal medial and lateral platforms and a relatively large stapedial foramen (approximately half the total length of the stapes; Fig. 8). The overall morphology is similar to that of other basal cynodonts, such as Thrinaxodon and Galesaurus. However, unlike the latter taxa the stapes of Vetusodon is proportionally longer lateromedially (L. C. Gaetano \& F. Abdala, pers. obs.). In some specimens of Procynosuchus, the stapes is proportionally long, resembling the element of Vetusodon, although they show a smaller stapedial foramen (e.g. RC 5, BP/1/226), but NHMUK PV R 37054 has a short stapes (Kemp, 1979). The crurae are straight and parallel to each other. The contact between the crurae can be distinguished on both platforms, being subtle in the lateral platform and more obvious in the medial one. The posterior crus is larger; its shaft is more robust than the anterior one and lacks the dorsal process. However, posteriorly, the lateral sector of this crus is somewhat inflected dorsally and bears a crest-like posterior margin. This portion of the posterior crus is probably homologous with the dorsal process observed in other cynodonts (e.g. Trirachodon, Luangwa and one specimen of Massetognathus) and represents the insertion area for the stapedial muscle (see Gaetano \& Abdala, 2015). The presence and
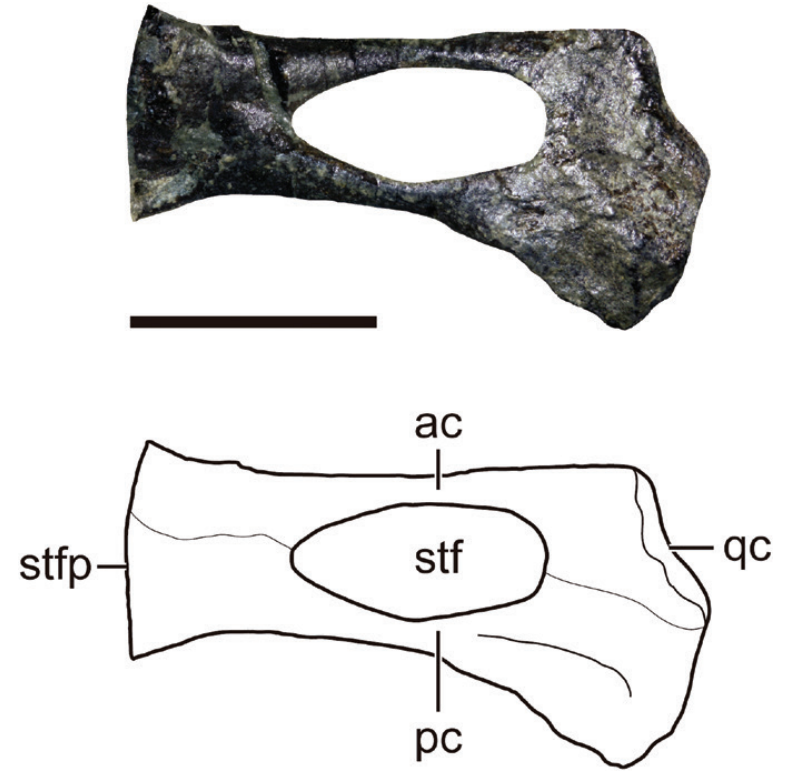

Figure 8. BP/1/7971. Left stapes of Vetusodon elikhulu. Abbreviations: ac, anterior crus; pc, posterior crus; qc, quadrate contact; stf, stapedial foramen; stfp, stapedial footplate. Scale bar: $10 \mathrm{~mm}$.

morphology of the dorsal process is variable among non-mammaliaform cynodonts, including the basal forms Thrinaxodon and Galesaurus (L. C. Gaetano \& F. Abdala, pers. obs.; Gaetano \& Abdala, 2015). The lateral platform is lateromedially larger than the medial one. The ventral surface of the medial platform is flat and its medial margin straight as observed in ventral view. The lateral platform bears a slightly convex ventral surface and a markedly convex lateral margin. The lateral surface of the stapes is smooth and is separated from the ventral surface by a well-defined crest, suggesting the presence of a cartilage covering. It has an anterolaterally and a posterolaterally oriented region. The anterior displacement of the quadrate in relationship to the facet of the squamosal produced the artificial contact of the anterolateral surface of the stapes with the quadrate, whereas the posterolateral surface is free (Fig. 1B). In Thrinaxodon, the quadrate contacts the posterolateral surface of the stapes (L. C. Gaetano \& F. Abdala, pers. obs.), whereas in Galesaurus there is an extensive contact between the quadrate and the lateral surface of the stapes (L. C. Gaetano \& F. Abdala, pers. obs.). A very restricted connection with a medial projection of the squamosal might have taken place at the point of inflection between these opposite-oriented surfaces. A broad and shallow squamosal sulcus is defined by the squamosal and the paroccipital process. From specimens SAM-PK-K10702 and CGP GHG141, it is clear that this sulcus ended close to the posterolateral 
corner of the stapes. Nevertheless, the open nature of this sulcus does not provide any evidence to suggest that it supported a post-quadrate tympanic membrane (see Gaetano \& Abdala, 2015).

\section{Craniomandibular joint}

This portion of the skull is best observed in BP/1/7971, and although the quadrate is slightly displaced anteriorly, its original position can be reconstructed easily.

The quadrate is inferred to have contacted the quadrate ramus of the epipterygoid, the lateral flange of the prootic and the squamosal. The paroccipital process does not contact the quadrate trochlea medially, because the squamosal is interposed between them (Fig. 1B). In anterior view, a clear separation is evident between the wide dorsal process of the quadrate and the much narrower dorsal process of the quadratojugal.

The quadrate dorsal process is triangular and is broken anteriorly along what is interpreted to have been a vertical groove. In anterior view, a rounded medial projection is present approximately halfway up the dorsal process of the quadrate. This projection is crushed and probably contacted the quadrate ramus of the epipterygoid and prootic. Alternatively, it might represent a displaced, broken portion of the squamosal, because no other cynodont presents a comparable structure. A relatively large quadrate foramen, which pierces the quadrate dorsal process anteroposteriorly, is present immediately above the quadrate trochlea, close to its lateral margin.

The rounded trochlea is well developed and robust. It expands both laterally and medially, considering the width of the dorsal process. A trochlear constriction is present on the medial half of the bone (Fig. 1B). Posteriorly, the trochlear constriction articulates with the descending process of the squamosal. The medial and the lateral trochlear condyles are similar in development. As observed ventrally, the medial one is rounded, whereas the lateral one is more rectangular.

The quadratojugal has a relatively short vertical process that is conical and directed medially. Ventrally, it is reconstructed as having contacted the quadrate below the trochlear surface, fitting into the lateral notch of the quadrate.

\section{Occipital plate}

The occipital plate is best preserved in CGP GHG141. In $\mathrm{BP} / 1 / 7971$, the occiput is deformed, and the posteroventral region, including the occipital condyles, is not preserved (Fig. 2C). In SAM-PK-K10702, the occipital region is crushed towards the right side of the skull, with two subrectangular bones, interpreted as the proatlases, present dorsal to the foramen magnum (Fig. 3E). The left proatlas is more complete and bears a small, rounded lateral projection.

The occipital plate is triangular and tipped anteriorly dorsal to the foramen magnum, whereas the ventral portion appears to be almost vertical. The postparietal is approximately square in posterior view (Fig. 2C). Anterodorsally, it wedges between the parietals, contributing to the very short sagittal crest. The postparietal is wider than the supraoccipital, which it contacts ventrally, and resembles the morphology of Progalesaurus (Sidor \& Smith, 2004: text-fig. 5). The supraoccipital is taller than wide and forms the entire dorsal margin of the foramen magnum (Figs $2 \mathrm{C}, 5 \mathrm{E})$. The postparietal area is somewhat larger than the supraoccipital, a condition also observed in Thrinaxodon, Progalesaurus, Platycraniellus and Lumkuia (Parrington, 1946; Hopson \& Kitching, 2001; Sidor \& Smith, 2004; Abdala, 2007). The opposite seems to be the case in Cynosaurus and Galesaurus (Jasinoski \& Abdala, 2017; Van den Brandt \& Abdala, 2018).

A conspicuous midline crest is present on the occipital plate and extends down the postparietal onto the supraoccipital, to the foramen magnum (Figs 2C, 3E). In SAM-PK-K10702, this crest is thin immediately above the foramen and expands dorsally on the occipital plate. The opposite is observed in $\mathrm{BP} / 1 / 7971$, with the crest being thin dorsally and becoming broad and robust ventrally (Fig. 2C). In CGP GHG141, an incipient crest is present but difficult to discern. Parasagittal depressions are present on either side of this crest.

The tabular is a fan-shaped element lateral to the postparietal and supraoccipital and forms almost twothirds of the posterior wall of the occipital crest (Fig. 2C). Together with the squamosal, the tabular forms a broad and rounded crest separating the occipital region from the zygomatic arch. Very close to its ventral margin, the tabular is pierced by the large, circular post-temporal fenestra, positioned immediately above the level of the dorsal border of the foramen magnum (Figs 2C, 5E). A shallow groove, delimited by subtle crests, extends anteromedially into the post-temporal fenestra. The groove and the post-temporal fenestra canal are directed anteromedially as judged from the occipital view. The ventral margin of the tabular is in contact with the exoccipital and the paroccipital process.

The exoccipital constitutes the ventromedial corner of the occipital plate and forms the lateral and part of the ventral margin of the foramen magnum (Fig. 2C). It has a short dorsal projection extending to the level of the post-temporal fenestra. The lateral margin of the exoccipital extends to the level of the medial margin of the post-temporal fenestra. The lateral extension of this bone is shorter in Thrinaxodon, Progalesaurus 
and subadults of Galesaurus (Parrington, 1946; Sidor \& Smith, 2004; Jasinoski \& Abdala, 2017). The exoccipital forms the semi-spherical occipital condyle. In SAM-PK-K10702, the condyles are ovoid structures that have medial contact below the foramen magnum (Fig. 3B, E). In CGP GHG141, they are similar in size to those of SAM-PK-K10702 but eroded posteroventrally. The rounded articular surface of the condyle is oriented posterolaterally and ventrally.

\section{MANDIBLE}

The lower jaw of SAM-PK-K10702 is robust, and the fused symphysis is almost vertical, with a very deep 'chin' (Figs 3B-D, 9), resembling the structure of Cynosaurus, although the symphysis is unfused in this cynodont (Van den Brandt \& Abdala, 2018). Although the ventral margin is missing in some parts, the horizontal ramus of the dentary does not seem to be very high. On the left is a well-developed masseteric fossa for adductor musculature that extends anteriorly to a point below the middle of the orbit (Figs 3D, 9 ). A notch at the base of the coronoid process of the mandible of Charassognathus was interpreted as the earliest evidence of invasion of adductor muscles on the lateral surface of the dentary of cynodonts (Botha et al., 2007; but see Kammerer, 2016). In addition to this, some basal cynodonts, such as Procynosuchus, Dvinia and Abdalodon, feature the masseteric fossa high on the vertical ramus of the dentary (Kemp, 1979; BothaBrink \& Abdala, 2008; Ivakhnenhko, 2013; Kammerer, 2016). Remaining cynodonts feature the masseteric fossa in the posterior portion of the horizontal ramus of the dentary. Halfway along the coronoid process height there is a pronounced lateral curvature of the dentary around the postdentary bar forming the adductor fossa. The tip of the coronoid process is located close to the postorbital bar and far from the posterior margin of the temporal fossa (Figs 3D, 9). A notable feature is that the posterior margin of the dentary covers a large part of the postdentary bar and is separated by a reduced space from the quadrate-articular joint (Fig. 3A, C). This condition, observed on both sides of the dentary, more closely resembles that of eucynodonts than that of Induan cynodonts (e.g. Thrinaxodon, Galesaurus). The postdentary bar is very robust. The splenial is a flat bone, and the suture between this element and the dentary is located medially in the lower jaw, halfway up the horizontal ramus, as is clearly observed on the right lower jaw. The splenial is totally fragmented on the left side. The reflected lamina of the angular is not preserved, but its base is present immediately behind the left pterygoid flange, at the level of the angle of the dentary. The prearticular is a cylindrical bar that expands laterally in the region of the articular (Fig. 3B).

\section{DENTITION}

There are four upper incisors and one canine in BP/1/7971, SAM-PK-K10702 and SAM-PK-K10596 (Figs 1B, 3B, 4B). The number of upper postcanine teeth varies strongly from 11 in SAM-PK-K10596 to only seven in BP/1/7971 (Figs $1 \mathrm{~B}, 4 \mathrm{~B}$ ). Only the roots of the upper right canine and some postcanines are preserved in CGP GHG141 (Fig. 5B, D). It is not possible to ascertain the number of postcanines in this specimen, but it was probably seven, judging from the sectioned alveoli and roots observed on the exposed surface of the broken left maxilla. The crown of the lower canine is also present in this specimen, inserted in the left paracanine fossa (Fig. 5B). Postcanine crowns are not visible in SAM-PK-K10702.

As observed in BP/1/7971 and SAM-PK-K10702, the incisors are simple, slightly recurved, conical teeth, lacking serrations and fluting on the enamel (Figs $1 \mathrm{~B}, 2 \mathrm{~A})$. Tooth wear is observed anteriorly on the tip of both I1 and the left I2 in BP/1/7971. The tips of the other incisors are broken off in this specimen. In BP/1/7971, there are replacement crypts for the first incisors on both sides. In the left crypt, the crown of a replacement tooth is present immediately behind I2. The right I3 and both I4 are not completely erupted in SAM-PK-K10702. A small diastema is present between the last incisor and the canine (Figs 2A, 4B).

The partly preserved upper canines of SAMPK-K10702 are conical in cross-section and slightly recurved at the tip. The surface bears longitudinal striations. Canines are broken at the base in BP/1/7971 and SAM-PK-K10596. They are ovoid in section, being longer than wide (Fig. 1B). In BP/1/7971, the right canine is larger in cross-section than the left one. Crypts for the replacement canines are present on both sides, and a new tooth is present on the right crypt. This partly exposed replacement tooth has a keeled distal margin. There is no diastema between the canine and the first postcanine (Figs 1B, 4B).

On the left side of BP/1/7971 the postcanine crowns are preserved, but on the right the teeth are eroded. The cross-sectional shape of the six right postcanines is clearly visible, and there is a hint of a small broken root of a seventh postcanine. The postcanines are single rooted, and the crown has a single conical cusp, slightly recurved and lacking evidence of crenulations or mesial and distal ridges (Fig. 2A). All the postcanine crowns are missing their tip except for PC5, which shows a distal flat surface. PC1 and PC3 are the largest elements of the series, with PC3 only slightly larger. PC2 is larger than PC4, which is followed by successively smaller elements. The crowns of the postcanines are almost circular in cross-section (Fig. 1B). Replacement crypts are observed at the side of PC3, PC4 and PC6. 
The 11 postcanines on either side of SAM-PK-K10596 are broken at their base, showing a circular crosssection (Fig. 4B). The size of the teeth is rather uniform, with some elements in the middle of the series being slightly larger than the others, and relative size varies between the right and left tooth rows. On the left side, at the level of the fourth postcanine, is the crown of an erupting tooth lacking the tip. It shows a single large cusp, with some backward curvature. Although also lacking the tip of the crown, a morphologically similar replacement element is present medial to the right PC10. In addition to these, several replacement teeth and crypts are also observed in this specimen, but replacement crowns are not preserved or clearly exposed.

\section{PHYLOGENETIC ANALYSIS}

Ten most parsimonious trees of 272 steps were obtained. The strict consensus tree is represented in Figure 10. Vetusodon is recovered as the sister group of Eucynodontia, being more derived than any other late Permian or even Induan cynodont, such as Thrinaxodon, Galesaurus and Platycraniellus. Unambiguous synapomorphies of the clade uniting Vetusodon plus Eucynodontia include the following: pterygoid quadrate ramus absent; epipterygoid quadrate ramus contacting quadrate; position of the dentary-surangular dorsal contact close to the jaw joint; upper tooth series extending below orbit; fused mandibular symphysis; and tall, steeply sloped mandibular symphysis, forming a distinct chin.

Our results show a basal monophyletic group of cynodonts that includes Charassognathus and the sister taxa Dvinia and Abdalodon. Two of these taxa, Charassognathus and Abdalodon, are from the Tropidostoma AZ of the Karoo, whereas Dvinia is a younger representative from Russia. Unambiguous synapomorphies of this basal group are as follows: external nares facing anteriorly; posterior extension of the parietal anterior to or reaching the occipital crest; and snout subequal in relationship to temporal region. However, in Abdalodon the scoring for the first two synapomorphies is unknown.

This basal group is followed by two successively more derived late Permian taxa: the geographically broadly distributed Procynosuchus and the Karoorestricted Cynosaurus. In pre-cladistic classifications, Cynosaurus was included in the family Galesauridae (e.g. Hopson \& Kitching, 1972; Kemp, 1982). This view is supported by the cladistic analysis presented by Sidor \& Smith (2004), whereas other analyses failed to find Cynosaurus as a member of Galesauridae (Abdala, 2007; Botha et al., 2007; Kammerer, 2016), a family that includes Galesaurus and Progalesaurus. The most parsimonious trees found here show that the latter genera form a monophyly of basal epicynodonts that excludes Cynosaurus and is supported by the following unambiguous synapomorphies: presence of infraorbital angulation; posterior postcanines with strongly curved main cusp; and lower postcanines lacking a cingulum.

We recovered a monophyletic group formed by Thrinaxodon + (Nanictosaurus, Platycraniellus) supported by only one synapomorphy: ectopterygoid does not contact maxilla (but the state character is unknown in Nanictosaurus).

Cynognathia and Probainognathia are recovered as monophyletic, constituting the Eucynodontia clade. In our analysis, Cynognathia is supported by six unambiguous synapomorphies: presence of a descending process of the jugal; well-developed posterior extension of the squamosal dorsal to the squamosal sulcus; deep squamosal sulcus in the lateroposterior exposure of the squamosal on the zygoma; temporal region widest posteriorly; serrated incisor cutting margins; and serrated canine margins. Probainognathia is supported by only three unambiguous synapomorphies: absence of parietal/pineal foramen; osseous palate posterior extent at the same level or posterior to the upper tooth row; and maxilla included in the margin of subtemporal fenestra.

Bremer supports (BS) and symmetric resampling (SR) values of the monophyletic groups recovered here are poor. The best supported groups are Cynosaurus + Epicynodontia, with a BS of seven and SR of 83, and Gomphodontia, with a BS of five and SR of 86. The Vetusodon + Eucynodontia clade has the next best Bremer support (BS $=4)$, but a $S R$ of 38 .

\section{DISCUSSION}

Cynodontia is the youngest therapsid lineage in the fossil record. Until recently, the oldest known cynodont fossils were from the latest Permian (late Wuchiapingian-Changhsingian). They were represented in the Karoo Basin of South Africa, the Usili Formation of Tanzania, the upper Madumabisa Mudstone of Zambia, the fissure-fillings deposits of Upper Werra Clay near Korbach in Germany and the Sokolki locality on the northern Dvina River of Russia (Sues \& Boy, 1988; Rubidge, 1995, 2005; Abdala \& Allison, 2005; Weide et al., 2010; Ivakhnenko, 2013). These cynodonts come from strata of the Daptocephalus AZ (formerly Dicynodon AZ) of the Karoo Basin and the Cistecephalus AZ of South Africa and the putative coeval faunas from Zambia and Tanzania (Angielczyk et al., 2014; Viglietti et al., 2015). Only recently have older cynodonts been recorded in the early late Permian (early Wuchiapigian) Tropidostoma AZ, consisting of two species, each represented by one specimen (Botha 
et al., 2007; Botha-Brink \& Abdala, 2008; Kammerer, 2016).

The Daptocephalus AZ of the Karoo Basin has the most diverse cynodont fauna from the late Permian, with three species represented, the most abundant being Procynosuchus delaharpeae ( 40 specimens), Cynosaurus suppostus (eight specimens; Van den Brandt \& Abdala, 2018) and the rare Nanictosaurus kitchingi (two specimens; van Heerden \& Rubidge, 1990). Vetusodon elikhulu is thus the fourth species of cynodont represented in the latest Permian of South Africa and is significant in that it has several unexpected features for cynodonts of this age (Abdala \& Smith, 2011). With a basal skull length of $\sim 18 \mathrm{~cm}$, it is the largest Permian cynodont and is also larger than all the succeeding Induan-aged cynodonts. Previously, the largest late Permian and Induan cynodonts were Procynosuchus (BSL $14 \mathrm{~cm}$ ) and Galesaurus (BSL $11.4 \mathrm{~cm}$; Jasinoski \& Abdala, 2017). In addition to its large size, Vetusodon is also robustly built, with a short and broad snout (Fig. 9). The postcanines, bearing a single conical, slightly posteriorly recurved cusp, present the simplest recorded morphology for any non-mammaliaform cynodont. Thus, it is the only non-mammaliaform cynodont in which the anterior dentition appears to have a more dominant role in food processing than the postcanines, a condition comparable to the gorgonopsians and the vast majority of therocephalians, including Moschorhinus (van Valkenburgh \& Jenkins, 2002). In contrast to the dental simplicity, the lower jaw shows an unexpected mammal-like anatomy, with the dentary extending posteriorly very close to the craniomandibular articulation. In this particular feature, Vetusodon is even more advanced than Induan cynodonts, such as Thrinaxodon and Galesaurus. It is intriguing that the location of the tip of the coronoid process in Vetusodon is positioned far anteriorly in the temporal opening, slightly behind the postorbital bar. This could be interpreted as an indication of the development of the temporalis muscle, with a long distance between its origin in the posterior sagittal and occipital crests and its insertion on the coronoid process, and is suggestive of a strong bite force by the anterior dentition.

Vetusodon also displays a new condition in the key evolutionary transition of forming a bony secondary palate. As is clearly manifested in BP/1/7971, the secondary palate remains open, but the posterior palatal projections of the maxillae and the anterior portion of the palatines are close to each other and partly cover the vomer, whereas projections of the premaxillae remain incipient. This suggests that the posterior part of the osseous palate came closer to its counterpart before than that of the anterior portion. The palatal projections of the maxilla and palatine are widely separated, and the vomer is exposed in the open secondary palate of the Lopingian Procynosuchus (Kemp, 1979). Despite being more basal, in the younger (Induan) cynodont Thrinaxodon, the palatal plates are very close but do not contact each other (Jasinoski et al., 2015).

It is interesting to highlight the overall resemblance in skull morphology (short and broad snout; skull width similar to skull length; Fig. 9) between Vetusodon and the coeval therocephalian, Moschorhinus. Other general similarities are the presence of an enlarged anterior dentition and the small and simple postcanine series. However, Vetsudon has seven to 11 postcanines compared with the one to three of Moschorhinus. These resemblances between Vetusodon and therocephalians were also noted by Kemp (1972), when comparing specimen SAMPK-K10596 with whaitsiid therocephalians. These conditions evolved independently in therocephalians and cynodonts at the end of the Permian. Vetusodon is the largest Permian cynodont (BSL $\sim 18 \mathrm{~cm}$ ), but Moschorhinus is considerably larger (BSL $\sim 26 \mathrm{~cm}$ ) in the Daptocephalus AZ (Huttenlocker \& Botha-Brink, 2013) and was one of the largest predators of the fauna. The independent evolution of similar morphologies between contemporaneous therocephalians and cynodonts also occurred in the Middle Triassic Cynognathus AZ, where baurid therocephalians and gomphodont cynodonts developed an osseous platform lateral to the postcanine dentition and complex buccolingually expanded postcanine teeth that allowed for rudimentary occlusion in both groups.

\section{PHYLOGENETIC IMPLICATIONS}

The existence of a monophyletic group including the two older species of cynodonts from the Tropidostoma $\mathrm{AZ}$ is a similarity between our hypothesis and that recently presented by Kammerer (2016). However, in our hypothesis the Russian Dvinia is also a member of this basal monophyletic group, whereas Dvinia, in addition to Procynosuchus, was part of a basal polytomy in Kammerer's (2016) hypothesis. Dvinia was the most basal cynodont in hypotheses by Hopson \& Kitching (2001) and Sidor \& Smith (2004), whereas it was recovered as the sister taxon of Procynosuchus by Abdala (2007), Botha et al. (2007), Ruta et al. (2013) and Van den Brandt \& Abdala (2018).

We recovered, for the first time, a monophyly formed by Thrinaxodon + (Nanictosaurus, Platycraniellus). Van den Brandt \& Abdala (2018) recovered these taxa as successive outgroups to Eucynodontia, whereas Abdala (2007), who did not include Nanictosaurus in his analysis, found Thrinaxodon and Platycraniellus to be successive outgroups to Eucynodontia. Nanictosaurus and Thrinaxodon were found as sister taxa in Kammerer's (2016) analysis that did not 

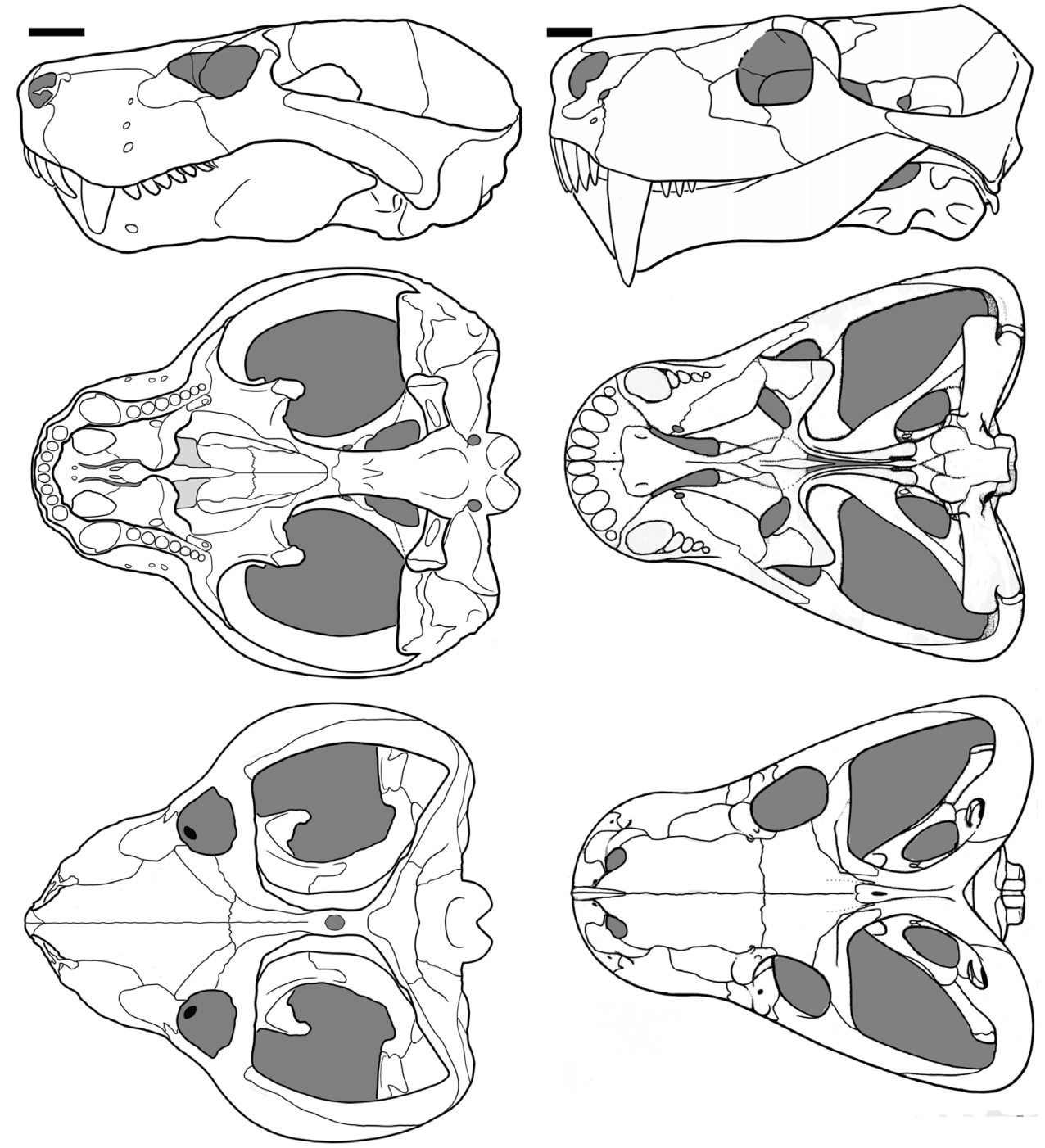

Figure 9. Lateral, dorsal and ventral reconstructions of the skulls of Vetusodon elikhulu (left) and Moschorhinus kitchingi (right). Scale bars: $20 \mathrm{~mm}$. Moschorhinus is modified from Durand (1991) and Huttenlocker (2009). Drawings by Enrique Guanuco.

include Platycraniellus. In the phylogeny presented by Liu \& Olsen (2010), Thrinaxodon and Platycraniellus formed a polytomy with Eucynodontia.

Therocephalians are recovered as paraphyletic with Microgomphodon as the sister taxon of cynodonts. There is an ongoing discussion about this subject in the literature. Abdala (2007) and Botha et al. (2007) proposed a non-monophyletic therocephalian group, although they found the whaitsiid Theriognathus as the sister taxon of cynodonts in their hypotheses. In contrast, Huttenlocker and co-workers (Huttenlocker, 2009; Huttenlocker et al., 2011, 2015; Huttenlocker \& Sidor, 2016; Huttenlocker \& Smith, 2017) have found a monophyletic Therocephalia in their cladistic hypotheses. The solution of this discussion is beyond the scope of the present work. However, we should mention that a much better sampling of taxa is necessary to address this issue properly. Taxon sampling by Abdala (2007) and in the present contribution, are perhaps the most appropriate, because they included several therocephalians, representing different lineages, and also a good sampling of cynodonts (six therocephalians and 23 cynodonts by Abdala, 2007). In the studies by Huttenlocker and co-workers, they have more extensive sampling of therocephalians (for example, 25 terminals by Huttenlocker et al., 2011 and 49 by Huttenlocker \& Smith, 2017), but in all cases only three basal cynodonts were included in the data matrices. Current hypotheses of cynodont relationships include 30-54 terminals (e.g. Liu \& Olsen, 2010; Ruta et al., 2013), 


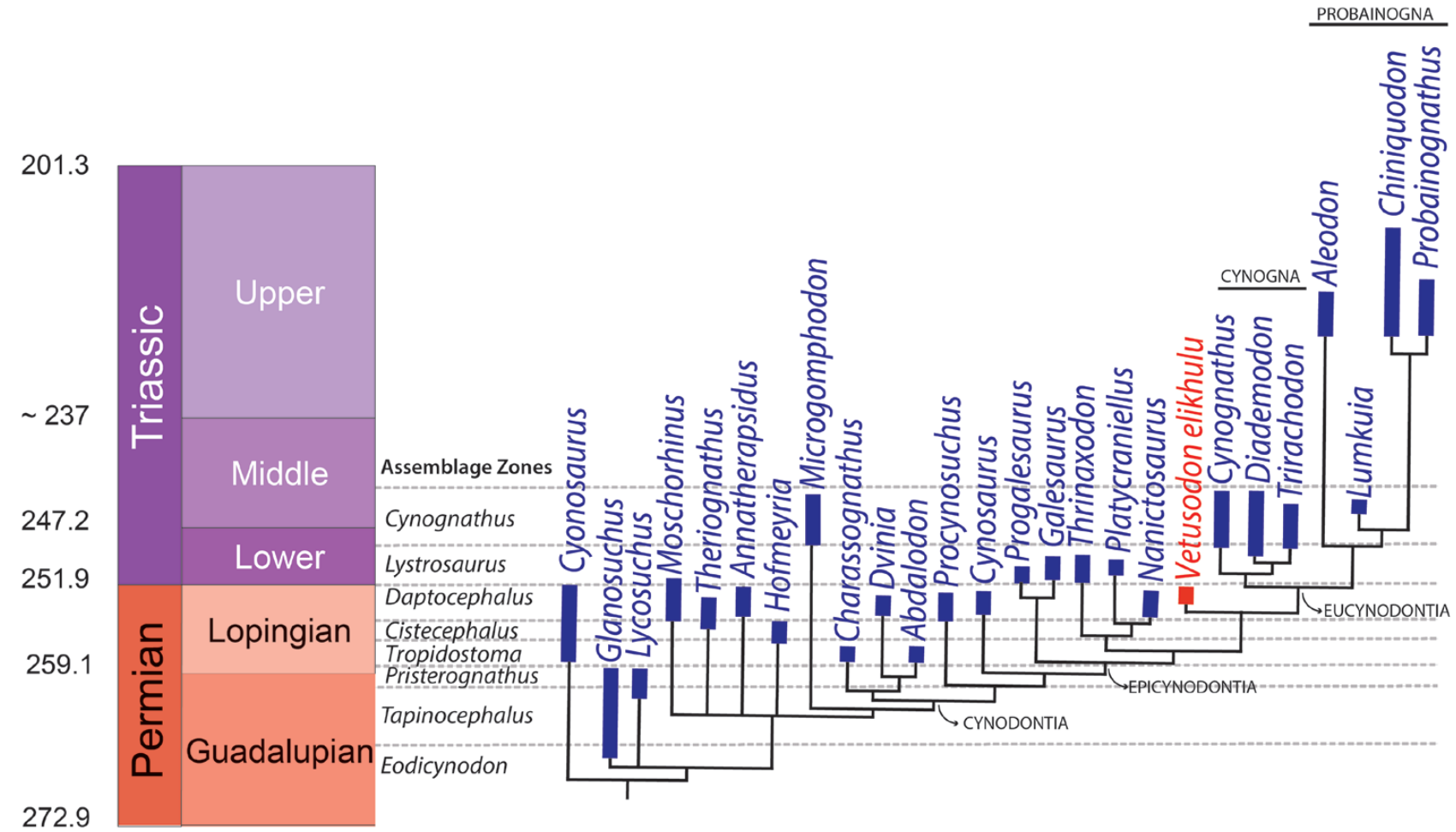

Figure 10. Strict consensus of the ten most parsimonious trees recovered in the cladistic analysis. Geological time scale after Walker et al. (2018). Abbreviations: Cynogna, Cynognathia; Probainogna, Probainognathia.

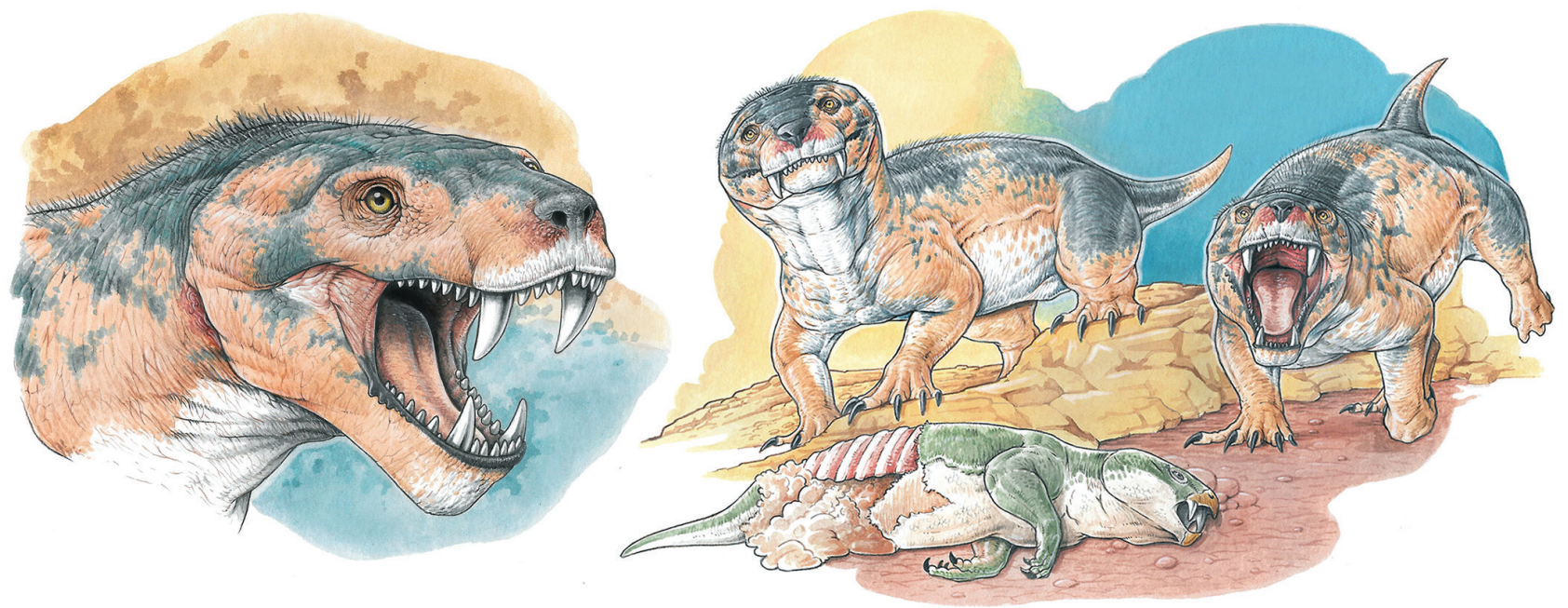

Figure 11. Life reconstructions of Vetusodon elikhulu. Artwork by Gabriel Lio.

whereas in the case of therocephalians they include 50 taxa (Huttenlocker \& Sidor, 2016; Huttenlocker \& Smith, 2017; Liu \& Abdala, 2017; Kammerer \& Masyutin, 2018). Support of therocephalian monophyly in recent hypotheses ranges from moderate/good
(Bremer support of three and a bootstrap value of 96 found by Huttenlocker \& Sidor, 2016) to low (bootstrap value of 67 found by Huttenlocker, 2009; bootstrap value of 51 found by Kammerer \& Masyutin, 2018). We consider that a renewed effort is necessary in the 
production of phylogenetic hypotheses, with the best representation of the diversity of the two groups, to obtain a clearer grasp of the phylogenetic status of therocephalians.

\section{CONCLUSION}

The new Late Permian cynodont Vetusodon elikhulu documents a surprising departure in the craniodental morphology of previously known basal members of this group. With a basal skull length of $18 \mathrm{~cm}$, it is the largest late Permian cynodont, and is also larger than the Induan Platycraniellus, Thrinaxodon and Galesaurus. Vetusodon features a remarkably wide snout, large incisors and canines, and tiny and unicusped postcanines (Fig. 11), representing the only case in non-mammaliaform cynodonts with unicusped postcanine teeth. This particular pattern of the dentition indicates a prominent role of the anterior dentition for eating. The dentary is exceptionally long and robust, and the posterior margin of the bone is located very close to the craniomandibular joint. This proximity of the dentary to the joint resembles the condition of younger eucynodonts. The secondary palate of V. elikhulu is short, incomplete and with the posterior portion of the maxilla partly covering the vomer, a unique condition in Late Permian cynodonts. A phylogenetic analysis including all basal cynodonts resulted in $V$. elikhulu being recovered as the sister taxon of Eucynodontia, and thus the most derived of the Lopingian to Induan cynodonts yet discovered. Vetusodon elikhulu is the only late Permian cynodont recorded near the Permo-Triassic extinction zone and demonstrates the existence of a more heterogeneous diversity of amniotes towards the end of the Palaeozoic.

\section{ACKNOWLEDGEMENTS}

We are indebted to B. Zipfel and S. Jirah (ESI), Nonhlanhla Mchunu (CGP) and C. Browning, Z. Erasmus and Z. Skosan (SAM) for access to specimens and loan for preparation. We also thank G. Groenewald and D. Wolvaardt, who found some of the specimens, and the skilled work of the preparators C. Dube (ESI) and A. Crean (SAM). We are grateful to the ESI team for their hospitality and for making us feel at home during our visit to the collections. The artwork of Figure 11 was made by Gabriel Lio, and Figure 9 was drawn by Enrique Guanuco, for which we are grateful. Reviews by Christian Sidor and an anonymous reviewer have been very helpful. Funding for the research was provided by PAST, National Research Foundation (NRF) African Origins Platform and the DST/NRF Centre of Excellence for Palaeosciences, South Africa, Consejo Nacional de Investigaciones
Científicas y Técnicas, Argentina (CONICET; PIP 11220150100760 CO to L.C.G.), Agencia Nacional de Promoción Científica y Tecnológica, Argentina (PICT 2014-1921 to V. Krapovickas and PICT 2015-2389 to N. Giannini). This is L.C.G.'s R-251 contribution to the IDEAN.

\section{REFERENCES}

Abdala F. 2007. Redescription of Platycraniellus elegans (Therapsida, Cynodontia) from the Lower Triassic of South Africa, and the cladistics relationships of Eutheriodonts. Palaeontology 50: 591-618.

Abdala F, Allinson M. 2005. The taxonomic status of Parathrinaxodon proops (Therapsida: Cynodontia), with comments on the morphology of the palate in basal cynodonts. Palaeontologia Africana 41: 45-52.

Abdala F, Barberena MC, Dornelles JF. 2002. A new species of traversodontid cynodont Exaeretodon from the Santa Maria Formation (Middle/Late Triassic) of southern Brazil. Journal of Vertebrate Paleontology 22: 313-325.

Abdala F, Jashashvili T, Rubidge BS, van den Heever J. 2014. New material of Microgomphodon oligocynus (Eutherapsida, Therocephalia) and the taxonomy of southern African Bauriidae. In: Kammerer CF, Angielczyk K, Fröbisch J, eds. Early evolutionary history of the Synapsida. Dordrecht: Springer, 209-231.

Abdala F, Smith RMH. 2011. Gran hermano en el Pérmico Superior: nuevo cinodonte de Sudáfrica representa la mayor especie del grupo al final del Paleozoico. In: IV Congreso Latinoamericano de Paleontología de Vertebrados, San Juan, Argentina, 21-24 September 2011.

Amalitzky VP. 1922. Diagnoses of the new forms of vertebrates and plants from the Upper Permian on North Dvina. Bulletin de l'Académie des Sciences de Russie, VIème série [Izvestiya Rossijskoj Akademii Nauk, VI seriya] 16: 329-340.

Anderson JM. 1968. The confused state of classification of the family Procynosuchidae. Palaeontologia Africana 11: 77-84.

Angielczyk KD, Steyer J-S, Sidor CA, Smith RMH, Whatley RL, Tolan S.2014. Permian and Triassic dicynodont (Therapsida: Anomodontia) faunas of the Luangwa Basin, Zambia: taxonomic update and implications for dicynodont biogeography and biostratigraphy. In: Kammerer CF, Angielczyk K, Fröbisch J, eds. Early evolutionary history of the Synapsida. Dordrecht: Springer, 93-138.

Benoit J, Jasinoski S, Fernandez V, Abdala F. 2017. The mystery of a missing bone: revealing the orbitosphenoid in basal Epicynodontia (Cynodontia, Therapsida) through computed tomography. Die Naturwissenschaften 104: 66 .

Boonstra LD. 1935. A note on the cynodont, Glochinodontoides gracilis Haughton. American Museum Novitates 782: 1-6.

Botha-Brink J, Abdala F. 2008. A new cynodont record from the Tropidostoma Assemblage Zone of the Beaufort Group: implications for the early evolution of cynodonts in South Africa. Palaeontologia Africana 43: 1-6.

Botha J, Abdala F, Smith R. 2007. The oldest cynodont: new clues on the origin and early diversification of the 
Cynodontia. Zoological Journal of the Linnean Society 149: 477-492.

Brink AS. 1963. Two cynodonts from the Ntawere Formation in the Luangwa Valley of Northern Rhodesia. Palaeontologia Africana 8: 77-96.

Brink AS. 1965. On two new specimens of Lystrosaurus-Zone cynodonts. Palaeontologia Africana 9: 107-122.

Coddington J, Scharff N. 1994. Problems with zero-length branches. Cladistics 10: 415-423.

Durand JF. 1991. A revised description of the skull of Moschorhinus (Therapsida, Therocephalia). Annals of the South African Museum 99: 381-413.

Estes R. 1961. Cranial anatomy of the cynodont reptile Thrinaxodon liorhinus. Bulletin of the Museum of Comparative Zoology 125: 165-180.

Fourie S. 1974. The cranial morphology of Thrinaxodon liorhinus Seeley. Annals of the South African Museum 65: 337-400.

Gaetano LC, Abdala F. 2015. The stapes of gomphodont cynodonts: insights into the middle ear structure of nonmammaliaform cynodonts. PLoS ONE 10: e0131174.

Goloboff P, Catalano SA. 2016. TNT version 1.5, including a full implementation of phylogenetic morphometrics. Cladistics 32: 221-238.

Goloboff P, Farris J, Nixon K. 2008. TNT, a free program for phylogenetic analysis. Cladistics 24: 774-786.

Haughton SH. 1918. Investigations in South African fossil reptiles and Amphibia (Part 11). Some new carnivorous Therapsida, with notes upon the brain-case in certain species. Annals of the South African Museum 12: 196-215.

Haughton SH. 1924. On cynodontia from the middle Beaufort beds of Harrismith, Orange Free State. Annals of the Transvaal Museum 11: 74-92.

Hopson JA, Kitching JW. 1972. A revised classification of cynodonts (Reptilia, Therapsida). Palaeontologia Africana 14: 71-85.

Hopson JA, Kitching JW. 2001. A probainognathian cynodont from South Africa and the phylogeny of nonmammalian cynodonts. Bulletin of the Museum of Comparative Zoology 156: $5-35$.

Huttenlocker AK. 2009. An investigation into the cladistic relationships and monophyly of therocephalian therapsids (Amniota: Synapsida). Zoological Journal of the Linnean Society 157: 865-891.

Huttenlocker AK, Abdala F. 2016. Revision of the first therocephalian, Theriognathus Owen (Therapsida: Whaitsiidae), and implications for cranial ontogeny and allometry in nonmammaliaform eutheriodonts. Journal of Paleontology 89: 645-654.

Huttenlocker AK, Botha-Brink J. 2013. Body size and growth patterns in the therocephalian Moschorhinus kitchingi (Therapsida: Eutheriodontia) before and after the endPermian extinction in South Africa. Paleobiology 39: 253-277.

Huttenlocker AK, Sidor CA. 2016. The first karenitid (Therapsida, Therocephalia) from the Upper Permian of Gondwana and the biogeography of Permo-Triassic therocephalians. Journal of Vertebrate Paleontology 36: e1111897.

Huttenlocker AK, Sidor CA, Angielczyk KD. 2015. A new eutherocephalian (Therapsida, Therocephalia) from the Upper
Permian Madumabisa Mudstone Formation (Luangwa Basin) of Zambia. Journal of Vertebrate Paleontology 35: e969400.

Huttenlocker AK, Sidor CA, Smith RMH. 2011. A new specimen of Promoschorhynchus (Therapsida: Therocephalia: Akidnognathidae) from the Lower Triassic of South Africa and its implications for theriodont survivorship across the Permo-Triassic boundary. Journal of Vertebrate Paleontology 31: $405-421$.

Huttenlocker AK, Smith RMH. 2017. New whaitsioids (Therapsida: Therocephalia) from the Teekloof Formation of South Africa and therocephalian diversity during the endGuadalupian extinction. PeerJ 5: e3868.

Ivakhnenko MF. 2013. Cranial morphology of Dvinia prima Amalitzky (Cynodontia, Theromorpha). Paleontological Journal 47: 210-222.

Jasinoski SC, Abdala F. 2017. Cranial ontogeny of the Early Triassic basal cynodont Galesaurus planiceps. Anatomical Record 300: 353-381.

Jasinoski SC, Abdala F, Fernandez V. 2015. Ontogeny of the Early Triassic cynodont Thrinaxodon liorhinus (Therapsida): cranial morphology. Anatomical Record 298: 1440-1464.

Kammerer CF. 2016. A new taxon of cynodont from the Tropidostoma Assemblage Zone (upper Permian) of South Africa, and the early evolution of Cynodontia. Papers in Palaeontology 2: 387-397.

Kammerer CF, Angielczyk KD, Fröbisch J. 2011. A comprehensive taxonomic revision of Dicynodon (Therapsida, Anomodontia) and its implications for dicynodont phylogeny, biogeography, and biostratigraphy. Journal of Vertebrate Paleontology 31: 1-158.

Kammerer CF, Masyutin V. 2018. A new therocephalian (Gorynychus masyutinae gen. et sp. nov.) from the Permian Kotelnich locality, Kirov Region, Russia. PeerJ 6: e4933.

Kemp TS. 1972. Whaitsiid therocephalia and the origin of cynodonts. Philosophical Transactions of the Royal Society of London. Series B, Biological Sciences 269: 1-54.

Kemp TS. 1979. The primitive cynodont Procynosuchus: functional anatomy of the skull and relationships. Philosophical Transactions of the Royal Society of London. Series B, Biological Sciences 285: 73-122.

Kemp TS. 1982. Mammal-like reptiles and the origin of mammals. New York: Academic Press.

Kemp TS. 2005. The origin and evolution of mammals. Oxford: Oxford University Press.

Lipscomb D. 1992. Parsimony, homology and the analysis of multistate characters. Cladistics 8: 45-65.

Liu J, Abdala F. 2017. The tetrapod fauna of the upper Permian Naobaogou Formation of China: 1. Shiguaignathus wangi gen. et sp. nov., the first akidnognathid therocephalian from China. PeerJ 5: e4150.

Liu J, Olsen PJ. 2010. The phylogenetic relationships of Eucynodontia (Amniota: Synapsida). Journal of Mammalian Evolution 17: 151-176.

Parrington FR. 1946. On the cranial anatomy of cynodonts. Proceedings of the Zoological Society of London 116: 81-197.

Rougier GW, Wible JR, Hopson JA. 1992. Reconstruction of the cranial vessels in the early Cretaceous mammal Vincelestes neuquenianus: implications for the evolution 
of the mammalian cranial vascular system. Journal of Vertebrate Paleontology 12: 188-216.

Rubidge BS, ed. 1995. Biostratigraphy of the Beaufort Group (Karoo Supergroup). Biostratigraphic series 1. Pretoria: South African Committee for Stratigraphy.

Rubidge BS. 2005. Re-uniting lost continents-fossil reptiles from the ancient Karoo and their wanderlust. South African Journal of Geology 108: 135-172.

Rubidge BS, Sidor CA. 2001. Evolutionary patterns among Permo-Triassic therapsids. Annual Review of Ecology and Systematics 32: 449-480.

Ruta M, Botha-Brink J, Mitchell SA, Benton MJ. 2013. The radiation of cynodonts and the ground plan of mammalian morphological diversity. Proceedings of the Royal Society B: Biological Sciences 280: 20131865.

Sahney S, Benton MJ. 2008. Recovery from the most profound mass extinction of all time. Proceedings of the Royal Society B: Biological Sciences 275: 759-765.

Sidor CA, Smith RMH. 2004. A new galesaurid (Therapsida: Cynodontia) from the Lower Triassic of South Africa. Palaeontology 47: 535-556.

Smith RMH, Botha-Brink J. 2014. Anatomy of a mass extinction: sedimentological and taphonomic evidence for drought-induced die-offs at the Permo-Triassic boundary in the main Karoo Basin, South Africa. Palaeogeography, Palaeoclimatology, Palaeoecology 396: 99-118.

Smith RMH, Rubidge B, van der Walt M. 2012. Therapsid biodiversity patterns and palaeoenvironments of the Karoo Basin, South Africa. In: Chinsamy-Turan A, ed. The forerunners of mammals: radiation, histology and biology. Bloomington: Indiana University Press, 31-62.

Sues H-D, Boy JA. 1988. A procynosuchid cynodont from central Europe. Nature 331: 523-524.
Tatarinov LP. 1968. Morphology and systematics of the Northern Dvinia cynodonts (Reptilia, Therapsida; upper Permian). Postilla Peabody Museum Yale University 126: $1-51$.

Van den Brandt M, Abdala F. 2018. Cranial morphology and phylogenetic analysis of Cynosaurus suppostus (Therapsida, Cynodontia) from the Upper Permian of the Karoo Basin, South Africa. Palaeontologia Africana 52: 201-221.

Van Heerden J. 1976. The cranial anatomy of Nanictosaurus rubidgei Broom and the classification of the Cynodontia (Reptilia: Therapsida). Navorsinge van die Nasionale Museum 3: 141-164.

Van Heerden J, Rubidge B. 1990. The affinities of the early cynodont reptile, Nanictosaurus. Palaeontologia Africana 27: $41-44$.

Van Hoepen ECN. 1916. Preliminary notice of new reptiles of the Karroo Formation. Annals of the Transvaal Museum 5: $1-2$.

Van Valkenburgh B, Jenkins I. 2002. Evolutionary patterns in the history of Permo-Triassic and Cenozoic synapsid predators. Paleontological Society Papers 8: 267-288.

Viglietti PA, Smith RMH, Angielczyk KD, Kammerer CF, Fröbisch J, Rubidge BS. 2015. The Daptocephalus Assemblage Zone (Lopingian), South Africa: a proposed biostratigraphy based on a new compilation of stratigraphic ranges. Journal of African Earth Sciences 113: 153-164.

Walker JD, Geissman JW, Bowring SA, Babcock LE. Compilers. 2018. Geologic time scale v. 5.0: the Geological Society of America.

Weide DM, Sidor CA, Angielczyk KD, Smith RMH. 2010. A new record of Procynosuchus delaharpeae (Therapsida: Cynodontia) from the Upper Permian Usili Formation, Tanzania. Palaeontologia Africana 44: 21-26.

\section{SUPPORTING INFORMATION}

Additional Supporting Information may be found in the online version of this article at the publisher's web-site:

File. Data matrix used in the analysis for the phylogenetic analysis in TNT and the same matrix presented as a nexus file. 